\title{
\#NEVERENOUGH: SOCIAL COMPARISON BY YOUNG WOMEN ON INSTAGRAM
}

\author{
by \\ Bailey Parnell \\ Bachelor of Arts, Media Production, \\ Ryerson University, 2015
}

\author{
A thesis presented to Ryerson University \\ and York University in partial \\ fulfillment of the requirements \\ for the degree of Master of Arts in \\ Communications and Culture.
}

Toronto, Ontario, Canada, 2020

() Bailey Parnell, 2020 


\section{Author's Declaration}

I hereby declare that I am the sole author of this thesis. This is a true copy of the thesis, including any required final revisions, as accepted by my examiners. I authorize Ryerson University to lend this thesis to other institutions or individuals for the purpose of scholarly research. I further authorize Ryerson University to reproduce this thesis by photocopying or by other means, in total or in part, at the request of other institutions or individuals for the purpose of scholarly research. I understand that my thesis may be made electronically available to the public. 


\title{
\#NEVERENOUGH: SOCIAL COMPARISON BY YOUNG WOMEN ON INSTAGRAM Bailey Parnell \\ Master of Arts in Communication and Culture \\ Ryerson University and York University, 2020
}

\begin{abstract}
As social media use continues to rise, studies have linked high social media use with rising levels of depression, particularly in young adults. This narrative has pervaded, yet in the research thus far, there is no general consensus as to causation or direction. What remains constant is that when mediators such as 'comparison' and 'envy' are introduced between social media use and depression, there is a negative correlation. In a qualitative study, I examine the connection between social comparison, Instagram use, and envy in young women. I conducted semi-structured interviews with a group of 10 female university students between the ages of 18-24. Interviews were analysed through qualitative descriptive analysis. Overwhelmingly, subjects engaged in frequent social comparison offline, which translated to frequent social comparison, made worse, on Instagram. As a result, participants admitted to feeling envious as well as other feelings like frustration, loneliness, anger, and overwhelm. However, users also reported positive experiences such as inspiration, humour, motivation, and happiness, when they are on Instagram. Offline affect proved to be the biggest moderators and indicators of comparison and the positive or negative experiences of the participants. This research may suggest future care in this area should focus on offline affect rather than the social networks themselves.
\end{abstract}




\section{Acknowledgements}

As a first generation undergraduate student and now first-in-the-family to complete a master's, let me be the first to say, "We did it!" As a part-time student also building a business, this thesis was the product of hard work paired with guidance and support from friends, family, mentors, and advisors along the way. May we all share in the pride of its completion. Specifically, many thanks to:

- To my research participants for being vulnerable and open with me. You have helped others.

- My supervisor, Dr. Anatoliy Gruzd, for being exactly the kind of guide I needed to succeed in this endeavour whether that be offering critical insight and chances to share my work in academia while also respecting my part-time status, need for autonomy, and career. This is how it should be done.

- My committee members, Dr. Jeremy Shtern and Dr. Natalie Coulter, for your insights and support, that undoubtedly improved my work.

- My MA cohort for being a fun and supportive group of peers who made space for each other's various diverse needs. I will never forget our special connection.

- My team in Ryerson Student Affairs for: giving me the freedom to work on my passion for digital wellbeing and \#SafeSocial; for believing in me and encouraging me to apply for an MA; for helping me through the process; and for funding the first half of my education.

- To my partner, Hamza Khan, for being an unwavering force of love and intellect. Whether I needed a laugh, feedback, a brainstorm, or a hug, you were there.

- To my ever-growing family of four parents and five sisters, let this be our success because I would never be me without you. We are so lucky. Cheers (of course)! 


\section{Dedication}

For the youth I work with who have been struggling with social media, know this research is just the beginning. Let's keep working towards \#SafeSocial. 


\section{Table of Contents}

Author's Declaration

Abstract iii

Acknowledgements $\quad$ iv

Dedication v v

List of Appendices vi vi vis

1. Introduction 1

1.1. Introduction to Instagram 4

2. Literature Review $\quad 8$

2.1. Social Comparison $\quad 10$

2.2. Social Media Use, Social Comparison, and Mental Well-Being 15

2.3. Instagram and Mental Well-Being 24

3. Methodology 28

3.1. Participants $\quad 29$

3.2. Recruitment $\quad 30$

3.3. Design $\quad 31$

3.4. Analysis $\quad 34$

4. Findings $\quad 37$

4.1. Social Comparison Offline 38

4.2. Social Comparison on Instagram $\quad 42$

4.3. Consequences of Social Comparison on Instagram 44

4.4. Moderators of Social Comparison and Resulting Feelings 48

4.5. Unexpected Findings $\quad 51$

4.5.1. Cognitive Dissonance

4.5.2. Social Pressure $\quad 54$

5. Discussion $\quad 57$

5.1. Relationship to Research Questions 57

5.2. Relationship to Social Comparison Theory 60

5.3. Relationship to Literature $\quad 65$

5.4. Implications $\quad 67$

5.5. Limitations \& Future Research

$\begin{array}{ll}\text { 6. Conclusion } & 77\end{array}$

$\begin{array}{lr}\text { Appendices } & 79\end{array}$

$\begin{array}{ll}\text { Bibliography } & 111\end{array}$ 


\section{List of Appendices}

- Appendix A - Recruitment email to program coordinators. 79

- Appendix B - Recruitment copy/social media posts. 81

- Appendix C - Recruitment poster and social media graphics. 84

- Appendix D - Initial recruitment form. 86

- Appendix E - Guiding interview questions for semi-structured interviews. 88

- Appendix F - Consent form. 93

- Appendix G - Thematic coding definitions. 99

- Appendix $\mathrm{H}$ - Additional participant quotes supporting frequent offline comparison.

- Appendix I - Additional participant quotes supporting a difference between upward, neutral, and downward social comparison.

- Appendix J - Additional participant quotes showing experiences of downward social comparison.

- Appendix K - Additional participant quotes showing the areas they compare themselves most.

- Appendix L - Additional participant quotes showing the frequency of social comparison on Instagram.

- Appendix M - Additional participant quotes showing the experience of appearance-related social comparison on Instagram.

- Appendix N - Additional participant quotes showing the experience of envy after using Instagram. 
- Appendix O - Additional participant quotes showing the collective frustration of the mindlessness of Instagram.

- Appendix P - Additional participant quotes showing positive feelings after using Instagram.

- Appendix Q - Additional participant quotes showing similarity as a moderator of comparison on Instagram.

- Appendix R - Additional participant quotes showing that offline mood moderated comparison on Instagram.

- Appendix S - Additional participant quotes showing a cognitive dissonance related to experiences of comparison on Instagram.

- Appendix T - Additional participant quotes showing feelings of social pressure related to Instagram. 


\section{Introduction}

In the last twelve years, social media has woven itself into the very fabric of our communications and culture and become integral to our lives: communication, news consumption, class participation, creating company culture, job searching, etc. As usage rates continue to rise dramatically, numerous studies have linked high social media use with rising levels of depression, particularly in the young adult demographic (Boak, Hamilton, Aldaf, Henderson, \& Mann, 2016; Primack, Shensa, Escobar-Viera, Barrett, Sidani, Colditz, \& James, 2017; Steers, Wickham, \& Acitelli, 2014). This is the narrative that has pervaded, yet in the research thus far, there is no general consensus with regards to whether social media actually causes depressive symptoms (such as sadness, fatigue, poor appetite, or loneliness) or not. While there are studies that show a strong correlation between social media use and depressive symptoms (Woods and Scott, 2016), there are also studies that show no correlation at all (Jelenchick, Eickhoff, \& Moreno, 2016; Weinstein, 2018). What seems to remain constant and more prominent is that when mediators such as comparison or envy are introduced between social media use and depression, there is a positive correlation (Steers et al., 2014;

Tandoc, Ferrucci, \& Duffy, 2015; Chua \& Chang, 2015; Chae, 2018). This may suggest that social media alone does not cause depression, but rather the acts of comparison or negative feelings of envy cause depression which is further accentuated by social media. For this reason, my research focuses on the experiences of comparison and envy when using social media. 
As social media use continues to rise, abstinence from social media, without consequence, is not an option for future generations and the youth of today. With our growing dependency on social media and the rising levels of depression alongside that dependency, we have a potential recipe for disaster. This is why research that might help us learn more about what is causing this depression is incredibly important at this time. This paper argues that the main reason for this depression are the acts of comparison and feelings of envy that are hyper focused on social media. If avoiding social media is becoming less of an option, especially for young people, we need to make it a healthier and more enjoyable space for them, which must be done by first understanding the true cause of mental health issues relating to social media and going beyond the simple metric of 'time spent on social media' to what is being experienced in that time, such as envy, loneliness, or social comparison. The lens through which I will investigate this issue is social comparison theory.

Social comparison theory, originally proposed by Leon Festinger (1954), is the idea that people compare themselves as a means of self-evaluating to understand their identity, and that when there is a lack of "objective or non-social" means available to evaluate our opinions and beliefs, comparison with others is ignited (Festinger, p. 118). This experience can happen offline and online and is prominent in young adults as you will see below. My research will focus on the experiences of social comparison in young women between the ages of 18-24 on Instagram. While older adults also compare themselves to others, feel envy, and use social media, young adults tend to compare themselves more (Callan, Kim, \& Matthews, 2015), potentially because they are in a 
phase of life where identity formation is changing rapidly as a result of life changes (Arnett, 2000; Erikson,1994) and therefore comparison is heightened as a means of getting to that identity definition. My goal is that any future mental health strategies that may result from my research could be used to help youth be well before, during, and after social media use.

In my research, I focused on young women particularly because women have been shown to rate higher on relational interdependence than men and to compare themselves to others more (Guimond, Chatard, Martinot, Crisp, \& Redersdorff, 2006; Gibbons \& Buunk, 1999), especially in the areas most popular on Instagram such as lifestyle, appearance, fashion, etc. It is however important to note that the consequences of social media use, good or bad, are not exclusive to women. Young men also compare themselves, experience self-esteem issues, and use social media in negative ways. I am cognisant that there are often moral panics about how young women, in particular, conduct themselves anywhere, and now also online, but since I am looking at social comparison specifically, it is the fact that young women engage in this more that drove me to this design. I conducted a series of 20 semi-structured interviews with 10 different participants. Since there was such a small sample size in my research, I also felt it would be more useful if the participants were similar so that the findings would be slightly more representative. Through my research, I aimed to learn how these young women experience social comparison, which has been previously linked to depression, how that experience translates to Instagram, and how those particular experiences connect to their affect. 
Beyond social comparison theory and Instagram as a ground for that to occur, this thesis assumes a view of media that is aligned with the Raymond Williams' (1985) school of thought in that it considers the "medium" of social media as part of a greater social and cultural landscape. Instead of studying the medium of social media, I aim to study how users experience social media and how the users themselves affect and alter their own experiences. This thesis assumes the content on social media and the people consuming the images are more important to the communications process than the platforms themselves. In this case, I am exploring how the content on Instagram affects my participants.

\subsection{Instagram}

Of all the social media platforms active in the current social media landscape, Instagram is one of the most noteworthy. "The service is both a photo-editing as well as a photo-sharing community" (Boer, 2016, p. 5) where the content is user-generated. Instagram launched in 2010 and has since grown to amass over 1 billion active monthly users with over 500 million of its users logging in daily (Our Story, 2019). Instagram is now the most engaged social network "with 2-7\% percent of users interacting with each post" via likes, clicks, comments, retweets, etc. As a point of reference, this means it is outpacing Twitter with "Twitter's $<0.2 \%$ [of users] engaging with each post" (Leone, 2018). Each day, Instagram users share over 95 million posts and give over 4.2 billion likes (Clarke, 2019). Similar to other social media, the network's demographic is younger (Smith and Anderson, 2018) with more than half of its users under 34 years old (Clement, 2019). More importantly for this study, only 3.3\% of Instagram users in 
Canada are between 13-17, whereas $24 \%$ are between $18-24$ years old (Clement, 2019) and $75 \%$ of all $18-24$ year olds are on Instagram (Chen, 2020) making this age range of particular interest. These young users primarily use Instagram for self-expression and surveillance of others (Alhabash and Ma, 2017; Sheldon and Bryant, 2016). These numbers paired with the fact that the 18-24 year old age range is still young, but old enough to consent to research of this nature is why my research will focus on the young adult demographic of 18-24 years old.

In addition to the youth demographic, Instagram is also used with more frequency and intensity by females (Gruzd, Jacobson, Mai, \& Dubois, 2018; Greenwood, Duggan \& Perrin, 2016; Duggan, 2015; Acar, 2008; Sheldon \& Bryant, 2016). It has also been shown that women are more likely to self-disclose about a variety of topics (Bond, 2009) and then link what they see from others to their self-esteem and body image (Franzoi, Vasquez, Frost, Sparapani, \& Martin, 2012; Grogan, 1999). With the aforementioned research in mind (Gruzd et al, 2018; Greenwood et al, 2016; Duggan, 2015; Acar, 2008; Sheldon \& Bryant, 2016; Bond, 2009), women are the largest demographic and most frequent users of Instagram as well as the most likely to personally compare and be affected by what they see from others, which is why I will be focusing exclusively on those who identify as female in my research.

Instagram came out as different than other forms of social media because it put the image at the forefront of its experience. Users are encouraged to share, edit, and consume visuals that may have accompanying textual elements in the form of captions 
and location tags. The move towards a more visual way of communicating has been philosophized and predicted for years. In addition to the historical belief that vision is the "noblest of the senses" (Jonas, 1953; Jay, 1993), we have also moved into what scholars call the "pictorial turn" or "iconic turn". Initially developed by William J.T. Mitchell (1995) in his book, Picture Theory, the pictorial turn is culture's "renewed interest in pictures and images" and that "our culture is more a product of what we watch rather than what we read" (The Pictorial Turn, 2015, p.1 ). Fast forward to today, and in one scroll of the explore page on Instagram, someone can see more curated images than ever before. If vision is humans' most prominent sense to perceive the world and there is a broader movement and acceptance of images as the bedrock of our understanding, it becomes easier to see why Instagram, in its visual glory, has risen to the top of all social media networks. If so many [young] people are spending so much time on this platform, it is imperative that we critically understand how people are using it, what ideals are being propagated here, and how both together influence users' behaviour and self-image.

In the time spent in this virtual space seeing visuals of people's best lives, we now have many opportunities for comparison to occur. Whereas 30 years ago, one might have only compared themselves to peers and celebrities on TV or in magazines, people can now compare themselves at an unprecedented rate to people all over the world who might have very similar opinions or abilities (therefore increasing the likelihood of comparison as you will see below). People can now also compare in an endless stream with the swipe of their thumb. The consequences of people comparing 
themselves at a potentially elevated rate on Instagram are, in part, what this paper endeavours to explore. It is because of Instagram's increasing popularity with youth, its hyper-curated culture, image-heavy nature, and its ability to provide a great deal of social comparison data that I will focus primarily on it in my research.

This thesis will explore the prevalence and experiences of social comparison in young women offline and online. The first research objective is to understand how young women are experiencing social comparison offline and to what degree. The second objective is to understand how those experiences of social comparison are translated to Instagram use. Finally, the third objective is to understand the affective experiences of these women as a result of comparing on and using Instagram. The thesis is structured as follows. To begin, a literature review will present previous studies on how social media relates to mental health. It will compare and contrast the existing research and demonstrate where my particular study fits in and fills a gap. The thesis will share my methodology and justification for conducting qualitative semi-structured interviews as well as share the findings and major themes from those interviews as they relate to comparison on Instagram and the resulting effect on people. It will discuss these findings through the lenses of social comparison theory and unexpected findings that emerged. Finally, I will share the implications of this research, the limitations, and suggestions for future research. 


\section{Literature Review}

If one were to only read news articles and blog posts about social media's impact on mental health and its connection to depression (even recent articles), they would see many headlines that suggest social media is causing people to be depressed (David, 2019; Howard, 2019; "Social Media Linked," 2019; "Social Media Use," 2019), and especially young people. Because of dramatic headlines such as the Daily Telegraph's "Cut social media use to reduce depression" ("Cut Social Media," 2018) or the Belfast Telegraph's outright "Social media 'causing teenage depression'" (Massey, 2019) one might not look much further into the research to uncover what scholars are actually finding, which is not as simple a correlation as the news tends to portray.

While some scholars have found a correlation between more time on social media and rising levels of depression (Kross, Verduyn, Demiralp, Park, Lee, Lin, \& Ybarra, 2013; Pantic, Damjanovic, Todorovic, Topalovic, Bojovic-Jovic, Ristic, \& Pantic, 2012; Woods \& Scott, 2016), others have found no correlation at all, as in high social media use did not independently predict reduced well-being or depression (Thorsteinsson \& Davey, 2014; Davila, Hershenberg, Feinstein, Gorman, Bhatia, \& Starr, 2012; Steers et al., 2014; Jelenchick et al., 2016). However, the vast majority of research has found that while time on social media may not in itself be an indicator of depression, when other variables come in to mediate the relationship between time on social media and declining mental health-mediators such as social comparison (Steers et al., 2014; Wang, Wang, Gaskin, \& Hawk, 2017; Vogel, Rose, Roberts, \& 
Eckles, 2014; Nesi \& Prinstein, 2015; Chae, 2018), envy (Tandoc et al, 2015; Jin \& Muqaddam, 2018; Krasnova, Wenninger, Widjaja, \& Buxmann, 2013; Li, 2019), low self-esteem (Chua \& Chang, 2015; Wang et al., 2017), offline affect (De Vries, Möller, Wieringa, Eigenraam, \& Hamelink, 2018), loneliness (Ingvadóttir, 2014), burnout (Liu \& Ma, 2018), rumination (Davila et al., 2012), or other demographic variables such as being female, multiracial, having a low income, or low education (Primack et al., 2017), there is more chance of a negative situation.

Furthermore, and to support these aforementioned findings, others found that when one of these mediators, such as comparison or envy, were not present, that social media could and did have a positive effect on their participants thus improving their mental health (Thorsteinsson \& Davey, 2014; Valkenburg, Jochen, \& Schouten, 2006; Weinstein, 2018; Ellison, Steinfield, \& Lampe, 2007; De Vries et al., 2018). Still further, of those who found a correlation (mediated or not), many also noted that they could not establish clear causation (Appel, Crusius, \& Gerlach, 2015; Hawi \& Samaha, 2017; Strickland, 2014; Weinstein, 2018; Pantic et al., 2012; Tandoc et al, 2015).

One of the potential reasons for the inconsistency in the research may be a result of the homogeneity of methods chosen by researchers in this area, with most of them using quantitative methods. This literature review will explore the nuances in the connection between time spent on social media and declines in mental well-being. As social comparison has emerged as one of the leading reasons for the correlation, much of this review will focus on social comparison theory and its mitigating effects on social media use and mental health. Finally, this review will briefly show similarities and 
differences in the research, gaps across the board, and how my research can fill these gaps.

\subsection{Social Comparison}

Social comparison theory, originally proposed by Leon Festinger (1954), is the idea that people compare themselves as a means of self-evaluating to understand their identity, and that when there is a lack of "objective or non-social" means available to evaluate our opinions and beliefs, comparison with others is ignited (Festinger, p. 118). This self-evaluation is believed by many (Dauenheimer, 2002; Sedikides, 1993; Sedikides \& Strube, 1997; Taylor \& Lobel, 1989; Wayment \& Taylor, 1995) to be thrice motivated by humans' need for: self-enhancement or using new information, like feedback, in such a way as to maximize the positivity of the self-concept or minimize its negativity (Dauenbeimer, Stablberg, Spreeman, \& Sedikides, 2002); self-verification or the desire to "maintain consistency between their self-conceptions and new self-relevant information" (Sedikides \& Strube, 1997, p. 213); and self-assessment or the pursuit of accuracy in self-knowledge (Dauenheimer et al., 2002. P. 91), as in wanting to ensure that what we think we know about ourselves is actually true. As a way to gain and maintain certainty in one's self-image, people compare themselves in areas such as appearance, opinions, career, skills, abilities, and other areas people deem part of identity-formation.

Comparison as a means of understanding our identity is inherently neutral-not negative or positive. For example, this can be as simple as someone getting the sense they are "tall" by comparing with everyone else around them and observing they are 
indeed taller than all. However, this comparison can also be bad for mental health for those who never evaluate themselves positively in relation to others. Whether motivated by self-enhancement, self-assessment, or self-verification, humans want to evaluate themselves against others in an effort to be better, and social comparison is the means to that evaluation regardless of whether that evaluation ends up being positive or negative.

Festinger hypothesized that "the tendency to compare oneself with some other specific person decreases as the difference between his opinion or ability and one's own increases" (Festinger, 1954, p.120). He goes further to explain: "a person does not tend to evaluate his opinions or his abilities by comparison with others who are too divergent from himself. If some other person's ability is too far from his own, either above or below, it is not possible to evaluate his own ability accurately by comparison with this other person. There is then a tendency not to make the comparison" (Festinger, 1954, p.120). This means that in an effort to more accurately understand ourselves, humans might look for people that resemble them in particular areas, and compare more. I took this lens into my research as a way to analyse what might make participants compare more or less. For example, a young adult is more likely to compare their abilities to that of other young adults. To continue the example, if those young adults also come from a similar geographical, racial, and/or financial background to the person comparing, the comparison will be even stronger, regardless of whether they deem themselves better or worse off (Festinger, 1954). 
Many scholars (Gruder, 1971; Goethals \& Darley, 1977; Wills, 1981; Tesser \& Campbell, 1982; Sulls, Martin, \& Wheeler, 2002) built on social comparison theory providing a deeper exploration into directional social comparison. While an upward social comparison would have someone figuratively looking up at someone and deeming them better-off, and a neutral or lateral comparison would have someone deem them relatively equal, a downward comparison would have someone looking down at their subject of comparison and deeming them worse-off than them in any area. Upward, downward, and neutral/lateral comparisons affect people in different ways. While frequent upward social comparisons have been shown to make us feel worse about ourselves (Morse \& Gergen, 1970; Wills, 1981), they can also sometimes be motivating or inspiring for the person making the comparison (Collins, 1989; Taylor \& Lobel, 1996), such as someone creating a vision board with photos to motivate them towards the life, house, or body they want.

On the other side of directional comparison, Thomas Wills (1981) suggested that "persons can increase their subjective well-being through comparison with a less fortunate other" (p. 245) or in other words, through downward comparison. This notion has further been supported by research (Gibbons, 1986; Stewart, Chipperfield, Ruthig, \& Heckhausen, 2012) showing downward social comparisons can improve our affect and self-esteem.

Regardless of direction, numerous studies (White, Langer, Yariv, \& Welch, 2006; Buunk, Collins, Taylor, Van Yperen, \& Dakof, 1990) have shown that engaging in more social comparison may lower self-esteem, cause depressive symptoms, and can make 
someone "more likely to experience envy, guilt, regret, and defensiveness, and to lie, blame others, and to have unmet cravings" (ibid, p. 36). Inversely, research has also found that those with lower self-esteem used more social comparison information to evaluate themselves while those with higher self-esteem used personal standards information (Wayment \& Taylor, 1995) - as in comparing themselves to their past selves instead of others. Furthermore, those with existing negative affect were also more likely to use downward comparison as a tool to feel better than those with an existing positive affect (Aspinwall \& Taylor, 1993). Essentially, this means people who are already feeling bad are more likely to use downward comparison information to make themselves feel better.

In the context of research concerning social media, social comparison theory seems to be primarily used to formulate research questions about people's experiences online, and most especially, people's experiences with appearance and body image on social media. Through the lens of social comparison theory, Jin, Muqaddam, and Ryu (2019) found that "more time on Facebook related to more frequent body and weight comparisons, more attention to the physical appearance of others, and more negative feelings about their bodies for all women" (p. 249). They posited that the more frequent social comparison via social media seemed to be the reason for more negative body image. Similarly, Ho, Lee, and Liao (2016) used social comparison theory to examine how comparison with friends and celebrities on social networking sites affected adolescents' body image. They found comparision with friends and celebrities positively correlated with body image dissatisfaction. Kim and 
Chock (2015), McGuirk (2017), and Lewallen and Behm-Morawitz (2016) were among other scholars who also used social comparison theory to explore body image issues as a result of comparing on social media.

Other scholars have widened the scope beyond body image and have used social comparison theory as a lens to examine social media-driven narcissism, envy, and the effects of viewing other's posts in general. Jin and Muqaddam (2018) used social comparison theory to explain the fact that for their subjects "perceived similarity between the post source and the viewer [was] the key mediator in explaining how viewers react[ed] to narcissistic posts [otherwise known as selfies]" (p. 37), as in if the subjects deemed the poster more similar to them, they were more likely to compare, which is a key part of social comparison theory. Chae (2018) used social comparison theory to explore the relationship between envy and observing the posts from social media influencers. They found that "individuals with high awareness of the self and others' evaluation (high public self-consciousness) and poor self-image (low self-esteem) more frequently engage in social comparison with influencers... [and that] the comparison behavior, in turn, predicts envy" (p. 257). In a similar vein, De Vries et al. (2018) used social comparison theory to explain the fact that people who had a high social comparison orientation offline were more likely to compare upwardly to strangers' happy posts and experience negative affect as a result. These two recent studies by Chae (2018) and De Vries et al. (2018) are the ones that align most with the findings of my research, as you will see below. 
Understanding that social comparison is a common and important part of the human experience, and the insights we gain from said social comparison can affect our self-image and mental health (positively and negatively), it is important to understand the circumstances that evoke frequent social comparison in young people and the grounds on which they take place. One of those grounds is social media today, and particularly, Instagram. This is also how a theory such as social comparison theoryone created long before social media existed-is still relevant and applicable as the basis of my work today. I believe social comparison is part of the human experience and that it has consequences on our thoughts, feelings, beliefs, and actions. I also believe that social media is but the most recent arena for this experience to take place. I feel, then, that it is imperative we understand how human's experience this phenomenon on social media, if it is made worse or better, and how people feel as a result.

\subsection{Social Media Use, Social Comparison, and Mental Well-Being}

The connection between social media and mental health is a growing area of research and therefore, the connection between Instagram and social comparison has not been extensively researched to the same degree as other areas of academic research. Earlier studies found a correlation between time spent on social media and declining mental health, such as heightened depression or lower well-being. Some of those studies include Pantic et al. (2012) who, by using the Beck Depression Inventory (BDI) in their questionnaire with high school students, found that "time spent on social networking in high school students [was] related to the risk for depression determined 
by the BDI" (ibid, p.92). Kross et al. found something similar in 2013 when they used experience sampling method (ESM) to ask participants how Facebook made them feel. Their work showed that Facebook use predicted declines in two components of subjective well-being: how people feel moment to moment and how satisfied they are with their lives (p. 4). In 2016, Woods and Scott surveyed over 400 secondary school students about social media use in relation to depression, anxiety, and poor sleep and found that all three variables individually related to social media use. These three foundational studies led other scholars to want to learn more about why the connection between social media use and mental well-being existed.

However, contradictory research supporting the exact opposite findings were also published around the same period showing time on social media was not independently correlated with depression or a decline in well-being. In 2012, Davila et al. conducted a two-part survey research with over 3000 young adults exploring their frequency and quality of social media interactions and found results indicated that depressive symptoms were associated with quality of social networking interactions (what they did and how they felt in their interactions), not quantity. Davila et al. clearly stated that "across both studies there was no evidence that social networking use was associated with depressive symptoms either concurrently or over time" (ibid, p.10) and they were not the only ones to come out with these findings.

In 2014, Thorsteinsson and Davey conducted a similar two-part longitudinal survey with participants 12 months apart and found that high social media use did not predict higher depression symptoms. Similarly, Jelenchick et al. used a combination of 
survey and ESM method and found no significant correlation between social media use and depression (2016) . They additionally felt it was too premature for the American Academy of Paediatrics to warn parents against social media use and too early to diagnose "Facebook depression" (O'Keefe \& Clarke-Pearson, 2011) as a widespread issue. In 2014, Steers et al. also found that when using a 14-day diary method, Facebook use was not independently associated with depression, but needed a mediating variable to be relevant. Exploration into these mediating variables then became the focus of research in this area, and eventually what led to my research design.

In response to the overly simplistic news reports and to early research that explored associations of time spent on social media and mental health, many other scholars began to explore why there was a correlation between time spent on social media and a decline in mental health and well-being. The majority of research in this area has since found that potential reasons for this correlation have more to do with mediating variables and what the content of a social media experience is like, not just the experience itself.

Primack et al. (2017) initially found that high use of multiple social media platforms and greater time spent on social media were associated with self-reported depression and anxiety. However, when they factored in multivariable analyses such as being female, multiracial, single, having a low income, or having little education in relation to depression and anxiety, time spent on social media was no longer significantly associated with anxiety and depression, which suggested that other 
issues like income or gender might alter anxiety and depression more than the amount of time spent on social media.

These findings were consistent with what Davila et al. (2012) previously found. Even though they did not find a connection between time on social media and depressive symptoms, they did find "more evidence that it is the quality, rather than the frequency, of social networking activities that is associated with depressive symptoms" (ibid, p.7). Particularly, experiences such as depressive rumination, characterized by deep fixated thought, appeared to strengthen the association between negative social networking interactions and depressive symptoms in general.

In addition to depressive rumination, Ingvadóttir (2014) conducted surveys with both high school and university aged students and found Facebook use to be correlated with loneliness, which is known to lead to depression (Cacioppo \& Hughes, 2006). In their research, Liu and Ma (2018) conducted surveys and found that social media use could lead to burnout and that burnout was actually the cause of more depressive symptoms. At the same time, De Vries et al. (2018) found that, after having participants view positive, negative, and neutral photos, a subject's negative affect going into the experiment determined if they engaged in social comparison with the subject, which lead to a negative mood; a subject going in with a positive affect would likely have experienced emotional contagion, which improved their mood. In addition to affect as a mediator, Wang et al. (2017) and Chua and Chang (2015) each found that participants' self-esteem mediated the relationship between time spent on social networking sites and subjective well-being - when participants had low self-esteem, 
social media was more likely to lower their subjective well-being and make them feel like they needed to edit their photos more to be socially appealing. As illustrated, substantial bodies of research point towards mediating variables such as burnout, Ioneliness, rumination, affect, and self-esteem as much greater indicators of depression or reduced well-being than simply time spent on social media.

In addition to these mediating variables, the two that emerged in the research as the most studied and most problematic were envy and social comparison. Envy, defined as the desire to have the qualities, possessions, or other attributes of someone else, was found by a number of scholars to be a true cause of the decline in well-being after using social media. For example, Krasnova et al. (2013) found that envy was a leading cause of frustration when their participants used social media and that envy mediated the relationship between social media and life satisfaction. Tandoc et al. (2015) also found, when looking into the connection between Facebook use and depression, heavy Facebook users did experience more envy and that envy (not time on social media) was the only positive predictor of depression. Jin and Muqaddam (2018) found envy significantly mediated the causal effects of the participants' attitudes towards posting content and posting their selfies. More recently, Li (2019) found envy to mediate the relationship between upward social comparison on social media and depressive symptoms, which leads to the largest area of concern with regards to social media's connection to declining mental well-being. It is the prevalence of social comparison that led me to use social comparison theory as a lens for my research. 
As demonstrated earlier, social comparison is not a new concept and has been historically linked to depression, lower life satisfaction, and lowered sense of well-being. In the areas of social media and mental health, scholars have tended to find a similar outcome. One study showed that time on Facebook was only associated with more comparison, and this mediating factor led to more depressive symptoms (Steers et al, 2014). Wang et al. (2017) found similarly that upward social comparison was associated with users' lower self-evaluation and their subjective well-being. Vogel et al. conducted a similar study and concluded that "participants who used Facebook most often had poorer trait self-esteem, and this was mediated by greater exposure to upward social comparisons on social media" (2014, p.206). Still more, Nesi and Prinstein (2015) found technology-based social comparison and feedback-seeking to be associated with depressive symptoms, which was made worse for women. A survey study in South Korea showed that the "effects of social media platforms on relative happiness were fully mediated by social comparison behaviour" among South Korean females (Chae, 2018, p.1661). It is clear through each of these works that social comparison was a better predictor of any future declines in well-being, and was also a precursor to other issues that cause reduced well-being such as low self-esteem and envy.

These mediators, and especially social comparison, are so important that when they were not present, many scholars also found the exact opposite conclusion: that social media improved the mental well-being of participants. Though Weinstein (2018) found, after in-depth interviews, no explicit correlation between time spent on social 
media and subjective well-being, they found that if participants were not experiencing feelings such as envy, they then experienced benefits (i.e., relational interactions contributing to closeness, self-expression facilitating affirmation of themselves, interest-driven exploration to gain inspiration, and browsing) that could lead to entertainment and admiration. Similar findings came from Thorsteinsson and Davey (2014) who found using the social part of the internet, such as instant messaging and social networking, was associated with a reduction in depression over time among compulsive internet users. When exploring the connection between friend networking sites and adolescents' well-being and self-esteem, Dutch scholar Valkenburg (2006) found that if participants received positive feedback on their profiles, social media enhanced their social self-esteem and well-being.

As mentioned earlier, De Vries (2018) also found that if users have a positive affect, they tended to view others' positive social media posts through an emotional contagion lens. Emotional contagion is the phenomenon whereby people take on the emotions, feelings, and potentially subsequent behaviours of another person. If someone delivers news to someone else with a giant smile on, the receiver will likely take on the emotion of happiness. Some scientists have discovered and posited that 'mirror neurons' in the brain are responsible for this phenomenon (Rizzolatti \& Fabbri-Destro, 2009). This is also how negative feelings can spread from one person to another, similar to how viruses are spread, hence the use of the word "contagion". In the case of the previously mentioned research, it meant they took on the joy of the poster, which of course improved their mood. As this research shows, social media 
has also been found to reduce depression, increase self-esteem, increase life satisfaction, and even improve a subject's mood. This tells us more strongly that it is the content and quality of social media interactions that matter more than the quantity of those interactions.

I have just highlighted numerous studies that show opposite findings in a way. Some find a correlation between time spent on social media while some show no statistically relevant connection. Others have found that a mediating variable is needed to explain the association between social media use and declining mental well-being, though many different variables have emerged as potential causes. Others still have shown that if those mediators are not there, social media can actually be a positive experience and be an equally positive influence on people's mental health. Often, these studies are observational and correlational, and therefore limitations abound when it comes to drawing causation between social media use and mental health and its potential mediating factors. For example, Appel et al (2015) found "the envy reaction to an attractive profile was more pronounced in the depressed group" (p.284) suggesting that depressed people may feel envy more and therefore experience it more on social media too. Both Hawi and Samaha (2017) and Chua and Chang (2015) suggested that "people with lower self-esteem may tend to depend on social media more" (Hawi, p.577) and that is why there is a correlation. Though Ingvadóttir (2014) found Facebook use correlated with loneliness in young adults, they also suggested that there may be other reasons for feeling lonely, such as moving away from home, and that it is also possible that lonely people turn to social media more as a way to connect. 
Other potential reasons for this connection between social media use and a decline in mental well-being came up as well. Upon doing her own literature review of research in this area, Strickland (2014) suggested that there may be another reason for the connection between social media use and depression such as that when using social media you are often engaging in more sedentary behaviours and displacing other behaviours we know contribute to positive mental health, such as physical fitness, being in nature, or spending time with friends and loved ones. Finally, Woods and Scott (2016), Pantic et al. (2012), Nesi and Prinstein (2015), and Weinstein (2018) all also suggested in their discussions that the direction is not known and that it is possible that depressed people just use social media more.

One can see there is a lot of nuance, complexity, and unknown variables in the research exploring social media's connection to mental health and depression. As mentioned earlier in this paper, the simplicity of popular news articles do not do justice to an area of research that is still developing and still largely inconsistent. A potential reason for the inconsistency in research findings may lie in the similarities and differences of the research. Though the findings of the research have been quite different, the methods and focus of the research have been quite similar.

Many similarities of studies exploring mental health and social media use are methodological. Perhaps the most glaring similarity throughout these studies is the very methods used to answer the research questions. Perhaps due simply to historical timelines, much of the research either focuses exclusively on Facebook (Moreno et al., 2011; Steers et al, 2014; Jelenchick et al., 2016; Tandoc et al., 2015; Appel et al., 2015; 
Ingvadóttir, 2014; Krasnova et al., 2013; Park \& Baek, 2018; Vogel et al., 2014; Kross et al., 2013) or focuses on all social media networks as a whole (Chae, 2018;

Charoensukmongkol, 2018; Hawi \& Samaha, 2017; Li, 2019; Nesi \& Prinstein, 2015;

Robinson et al., 2015; Verduyn et al., 2017; Wang et al., 2017; Weinstein, 2018; Yang et al., 2018). The very fact that many researchers studied Facebook alone speaks to how fast social media changes. You will see that most of the research focusing exclusively on Facebook was published in/before 2016. Though Instagram launched in 2010, by 2012 it had gained mass popularity hitting 80 million users ("Our Story," 2019). At the time the thesis was written, Instagram has become the most popular with young people as well as the network they spend the most time on, and take most seriously.

\subsection{Instagram and Mental Well-Being}

Similar to any other communications tool, Instagram can and has been studied through multiple lenses. Instagram has been explored and shown to be an effective business marketing tool that can influence purchasing decisions and users' ideas (Jin, Muqaddam, \& Ryu, 2019; Djafarova \& Rushworth, 2017; De Veirman, Cauberghe, \& Hudders, 2017). It has also been researched as a new avenue and effective visual tool for modern journalism (Maares \& Hanusch, 2018; Bell, Owen, Brown, Hauka, \& Rashidian, 2017), as well as for its ability to influence people in politics (O'Connell, 2018; Ekman \& Widholm, 2017) and political campaigns (Lalancette \& Raynauld, 2019; Bossetta, 2018). As we get closer to the content of this thesis, Instagram has also been shown extensively to be a place that can promote unhealthy connections to body 
image (Wagner, Aguirre, \& Sumner, 2016; Kleemans, Daalmans, Carbaat, \& Anschütz, 2018; Slater, Varsani, \& Diedrichs, 2017; Casale, Gemelli, Calosi,Giangrasso, \&

Fioravanti, 2019) while simultaneously being a great tool for self-expression (Weinstein, 2018; Lee, Lee, Moon, \& Sung, 2015).

With regards to Instagram's connection to declining mental well-being as this paper is interested in, fewer works, most within the last year, have focused on Instagram specifically, the main ones I found being: Chua \& Chang, 2015; De Vries et al., 2018; Jin \& Muqaddam, 2018; Tiggemann et al., 2018; and Andalibi, Ozturk, \& Forte, 2017. While still valuable, Facebook-only studies seem less representative of the social media experience at the time of writing. Undoubtedly, with more time, more Instagram studies will emerge including my present research, which is focused on Instagram specifically. When paired with others' research before it, the collective findings will ultimately be more generalizable and relevant to younger generations of today.

Another similarity in the research of this area is that the majority of researchers used quantitative surveys as their main method and furthermore used similar designs in their questionnaires. Many researchers sought quantitative data to measure what might be the most nuanced and qualitative concept we know: our feelings. After a survey, many used chi-squared statistical analysis to come to their conclusions. Many surveys also used already-existing and accepted measures to operationalize the broad concepts researchers were studying. Concepts like comparison and self-esteem were measured using established measuring scales such as the lowa-Netherlands 
Comparison Orientation Measure (INCOM) and the Rosenberg Self-Esteem Scale (RSES), respectively. To measure depression alone, Steers et al. (2014) and Tandoc et al. (2015) used the Center for Epidemiologic Studies Depression Scale (CES-D); Woods and Scott (2016) used the Hospital Anxiety Depression Scale (HADS); Jelenchick et al. (2016) used the Patient Health Questionnaire-9 (PHQ); and Primack et al. used the Patient Reported Outcomes Measurement Information System (PROMIS). While these four surveys are designed differently to capture different nuances, they are still measuring the same concept similarly for the participant-through questions on a survey. Though valuable findings emerged from this method, my goal was to potentially expose something new by changing from a survey to an interview. While a few researchers designed visual experiments (Jin \& Muqaddam, 2018; Vogel et al., 2014; De Vries, et al., 2018) or used experience sampling method (Jelenchick et al., 2016; Kross et al., 2013), they still turned their findings into quantitative analyses whereas my goal with the present research is to share qualitatively as well. Weinstein (2018) and Chua and Chang (2015) were the only studies I came across that incorporated qualitative interviews and the voices of their subjects into their research. Weinstein (2018) combined quantitative findings from earlier research with the voices of participants. Through this method, they showed that participants themselves are capable of explaining the nuances and negative and positive aspects of their social media experiences. While it is important that studies using different surveys have generated different results, psychological research generally understands that replicability is needed to be more convincing and therefore only a correlation can be 
drawn. To more clearly understand the nuances, one requires a qualitative approach that builds on theoretical insights and may later contribute to the development of measuring tools that enlighten the connection between social media use and well-being.

Though there is no explicit consensus in the research findings, most of the papers reviewed for this thesis work found evidence to suggest that social media is not the main cause for concern, but rather that offline feelings and mediators like envy, comparison, or self-esteem, seem to impact mental well-being more (Steers et al., 2014; Wang, et al, 2017; Vogel et al, 2014; Nesi \& Prinstein, 2015; Chae, 2018; Tandoc et al, 2015; Jin \& Muqaddam, 2018; Krasnova et al, 2013; Li, 2019; Chua \& Chang, 2015; Wang et al., 2017; De Vries et al, 2018; Ingvadóttir, 2014). Furthermore, in the papers reviewed for this thesis, social comparison emerged as the most common mediator linked to a decline in well-being as well as a precursor to other negative feelings such as envy and low self-esteem.

In sum, my research addresses and responds to many of the findings and gaps in this area. It will introduce a qualitative, interview-based study so that a more nuanced explanation about feelings from the subjects themselves can be understood. The research focuses on Instagram particularly, as it is still underserved in well-being related research, but yet is the most popular with youth today. Finally, this research will be spread out over multiple interviews with the same subjects to account for changes in feelings over time as many scholars did not do. The goal is that filling these gaps 
may expose new findings and/or help clarify the inconsistencies in the current research about social media use and mental well-being. 


\section{Methodology}

This qualitative study was designed specifically to add to current research and introduce the voice of subjects into this space by hearing directly from people about their online experiences and the resulting feelings. Most studies in this area are situated in the positivist paradigm and endeavour to use scientific tools and proof to reveal the believed true nature of people's feelings. This might be because this is a generally new area of study and researchers may be trying to explore and define the "reality" before they can question that reality like one would in the post-structuralist paradigm (Grbich, 2013, p. 6). The present study, however, was inspired by

Weinstein's (2018) post-positivist approach and is, too, operating from a post-positivist paradigm where the goal was to objectively learn about the subjects' reality versus trying to manipulate it.

Informed by the post-positivist paradigm, a qualitative descriptive analysis study was designed. I began without an already-formed hypothesis about what would be found in participants' experiences on Instagram as it relates to their mental health. Rather, participants were interviewed, and at one point observed, in an effort to discover the meaning they placed on their experiences. This is critical because going into this research, I am designing it to respect and honour the lived experience of young people and not try to impose my own adult understanding onto them. I am investigating participants' perceptions of how they see their comparisons and reality and not looking at the empirical reality of 'how things are'. After semi-structured interviews, interview transcriptions were analyzed through a qualitative descriptive 
analysis. This allowed the ability to consider nuances in the language participants used when discussing their experiences of comparison on Instagram.

\subsection{Participants}

Participants of this study were 10 female-identified students at Ryerson University between the ages of $18-24$. As mentioned in the literature review, there was an effort to narrow the group to just young women as they tend to be the most active online, potentially more likely to compare in the areas most popular on Instagram, and have been shown to be more affected by these comparisons. In addition to age and gender, participants were required to speak fluent English. This was important because discussing feelings is extremely nuanced in any language and this could ensure a clear understanding of participants' explanations. It was also required that all participants be actively enrolled as full-time undergraduate students at Ryerson University, allowing for slightly more comparable experiences and ease of participation. Participants were also required to have an active personal Instagram account, operationalized as someone who checks their personal Instagram feed at least once per day and who posts on their own account at least once every two weeks. This also ensured participants were not just viewers, but actually contributing to the content of the platform. Exclusion criteria was in response to the inclusion criteria. Participants could not have private accounts, could not be running the Instagram account on behalf of a brand, and could not be users who do not engage. 


\subsection{Recruitment}

Ethics approval was acquired and granted by the Research Ethics Board at Ryerson University. Recruitment for this study took place online since it was active online users being looked for. Students were offered \$20 CAD to participate in the study; $\$ 10 \mathrm{CAD}$ at the beginning of the first interview and $\$ 10 \mathrm{CAD}$ at the beginning of the second interview. If a participant withdrew part-way through the first or second interview, they would still get the $\$ 10$ for that interview. To recruit people, an email was sent to all program administrators of undergraduate programs requesting they forward this opportunity to participate in research to their students. A copy of this email is included in Appendix A. Simultaneously, RU Student Life, the largest student-facing online brand at Ryerson, agreed to share recruitment posts on their social media accounts including their Instagram, Twitter, Facebook, Snapchat, and e-newsletter. Copies of sample social media posts and all visual recruitment material used are included in Appendix B.

All communications linked to an initial recruitment form, which was hosted on Ryerson Google Forms and collected emails of interested participants. Since this study was a small sample size focused more on the experiences of young women on Instagram and less on how that compares with participants' social location, no demographic data was collected beyond the inclusion metrics of identifying as female and being between 18-24 years old. More comprehensive demographic data was considered unnecessary for this study. A copy of this initial recruitment form is included in Appendix C. In less than one week, over 50 people responded to the 
recruitment form. Once I had a list of interested names, I continued with convenience sampling to book the first 10 students who committed to scheduling. Though it was not formally collected, it emerged in interviews that these participants varied widely in year of study as well as program of study. Though it is possible participants knew each other, it is unlikely given the previous statement and the fact that there was absolutely no digital or physical overlap or identity disclosure between participants from my side.

\subsection{Design}

This study consisted of conducting two 30-minute semi-structured interviews with 10 participants approximately one month apart. This sample size of 10 was feasible but still large enough for thematic saturation to emerge. Though focus groups would have allowed for a greater number of experiences to be shared, one-on-one interviews allow for a deeper story to be told about their perceived experiences of comparison and affect as a result, which is part of the goals of this study. In addition, if young adults are asked to disclose personal situations in front of a group of their peers instead of privately with a researcher, there would be a higher likelihood that their social desirability bias would get in the way of accurate and honest recalls of their experiences. Even with the one-on-one interviews, Anton Nederhof's "Methods of Coping With Social Desirability Bias" (1985) was still consulted to mitigate this issue in the research design. Semi-structured interviews were chosen as the preferred method because they ensured there was some structure and guidance for the participants, but also gave me freedom to pull on meaningful threads when they arose. 
The 10 participants were interviewed twice about their experiences on Instagram for a couple of reasons. Firstly, because we were discussing the sensitive subject of feelings, two interviews allowed participants to build rapport and feel more comfortable with me as well as made it more likely they would share personal information in the second interview. Interviewing participants twice also accounted for the fact that feelings change and may have been 'off' in the first interview. So, the second interview allowed for a fuller picture to be created about their experiences and allowed them to explain themselves had they been thinking about something since the first interview.

The interviews lasted between 25 minutes to 30 minutes. The first interview focused more on experiences of social comparison while the second interview focused more on their experiences on Instagram. This order was chosen because, as shown in the literature review, social comparison is a normal human behaviour long before the advent of social media (Dauenheimer, 2002; Sedikides, 1993; Sedikides \& Strube, 1997; Taylor \& Lobel, 1989; Wayment \& Taylor, 1995). I believed there would be a connection between those who compared themselves frequently offline and those who also did online. In designing the questions around comparison in the interviews, the lowa-Netherlands Comparison Orientation Scale (INCOS), a self-report scale to measure social comparison, was also consulted for inspiration and guidance. For example, though not all questions were asked in an effort to respect their authentic experiences and retellings, one question on the INCOS asks "I always pay a lot of attention to how I do things compared with how others do things." This question then 
informed my guiding questions. A copy of the guiding interview questions for both interviews can be found in Appendix E.

Interviews were recorded on audio and the interviewees' names were omitted and sent for transcription to Rev.com, a transcription service that offers confidentiality agreements and secure storage and transmitting using 128-bit SSL encryption. Rev.com also signed a non-disclosure agreement. Once they transmitted the files, Rev deleted them off their servers as indicated in the contract, and they were saved on the secure Ryerson Google Drive, complete with two-step verification and added security specifically for partnerships in academia. Following the interview phase, a qualitative descriptive analysis was conducted, and more specifically, a qualitative descriptive analysis of major themes in the experiences of the participants was conducted.

Consent was obtained in both the initial recruitment form and later in a more detailed consent form. A copy of this consent form can be found in Appendix F. Considering we would be discussing mental health, it was possible participants could have been negatively triggered by our discussion. This was mitigated by having a protocol in place that was informed by counsellors at Ryerson. If needed, distressed participants would personally be guided to the Ryerson Centre for Student Development and Counselling so that they could seek same-day care soon after. I would also remain available to these students via email for up to one year after the research was complete.

The first interview inquired about participants' general experiences of comparison. They were asked if they considered others' opinions often; if they 
compared themselves often; if those were upward, downward, or neutral comparisons; and if there were particular areas of life in which they compared themselves more (Appendix E). To make participants feel comfortable and to mitigate social desirability bias, they were told that comparison is not inherently negative but more of a tool humans use to construct identity. They were also explained the differences between upward, downward, and neutral comparisons using a visual I designed (Appendix F).

At the beginning of the second interview, participants were given their remaining $\$ 10$ and asked if they had thought at all about the topics we discussed. In this interview, they were asked more about their Instagram use and if they compare themselves on Instagram; how it related to offline; if they experienced envy or any other feelings often on Instagram; and if they had advice for younger people using Instagram (Appendix E). In the second interview, we also conducted a short observation where participants pulled out their personal Instagram accounts and walked through the first five or so photos on their feed. In an unstructured natural way, questions were asked about who they were following and why, why they were liking certain photos, and what they liked to see most.

\subsection{Analysis}

To analyze the interview data, I performed a qualitative descriptive analysis. Firstly, I performed a line-by-line reading of transcriptions. During this phase, I kept a record of major themes that appeared throughout all subjects. These included themes in what subjects answered on the given questions, but also any underlying themes in how they described their experiences. These themes were then compiled and 
organized into nascent categories such as "compares a lot," "comparison on Instagram," "frustration with mindlessness," "cognitive dissonance," or "social pressure." A definition of each theme can be found in Appendix G. For categories such as "compares a lot" or "comparison on Instagram" they often outright answered the question by saying something like 'yes, I do compare myself a lot'. However, for themes such as "frustration with mindlessness," "cognitive dissonance," or "social pressure," these were extracted. A "frustration with mindlessness" note would come when participants expressed a negative sentiment associated with either the amount of time they were spending "absentmindedly" on Instagram or if they felt they were "wasting time" when on Instagram, regardless of how much time. A "cognitive dissonance" quote would be noted when participants expressed competing values and behaviours such as knowing something was wrong, but doing it anyways, loving and hating someone they follow at the same time, or recommending that children act the exact opposite of how they conduct themselves online. Finally, "social pressure" was noted when participants expressed that it was the opinions of others that makes them act the way they do online, even when it is to their detriment. If they noted pressure from friends, society, or "that's just how things are done," it was recorded as a sentiment of feeling social pressure.

Upon second reading, I conducted a deeper analysis where, using the categories generated, I collected quotes that fell in line with those categories. In an effort to be true to the subject's voice, many exact quotes are used in the Findings and Discussion sections below with many more included in appendices, though their 
identities have been anonymized, referring to them as a personal pseudonym. The goal in designing a qualitative study was that a more in-depth look at the experiences of young women online will further add to the work in this area and may later guide the inconsistencies around whether social media causes a decline in mental health in one direction or another. 


\section{Findings}

The research questions of this study centred around: 1) understanding if and how young women are engaging in social comparison offline, 2) understanding if and how young women are engaging in social comparison on Instagram, and 3) what the results of those experiences were on their affective well-being. All recruited participants joined Instagram between the ages of 11-13 years old. They engage in a lot of upward and neutral social comparison offline. Those who reportedly engage in downward comparisons demonstrated feelings of guilt for doing so. Most participants feel social comparison is more prevalent and made worse when using Instagram. The participants' similarity to the subjects of comparison, as well as their offline affective state, proved to be the biggest moderators and indicators of comparison and the resulting feelings after using Instagram. Though "moderators" and "indicators" are not traditionally qualitative terms, I use them here to describe the experiences that seem to either emphasize or de-emphasize the subjects' feelings (moderators) or could help determine what those feelings would be (indicators). Participants admitted to feeling envy, frustration with the mindlessness and habit of it, as well as many other feelings like loneliness, anger, overwhelm, etc. after comparing themselves often on Instagram. However, users also reported positive feelings such as humour, inspiration, motivation, and happiness when they are on Instagram. Overall, there was often a cognitive dissonance (defined as "a feeling of mental discomfort.. involving conflicting attitudes, beliefs, or behaviors"(McLeod, 2018)) in their answers and behaviours about 
comparison on social media. Though often feeling negatively after using Instagram, social pressure and norms seem to be keeping them engaging on this platform.

\subsection{Social Comparison Offline}

$R Q$ \#1: Are young women engaging in social comparison offline? If yes, how do they experience this?

To investigate the first research question around understanding if and how young women are engaging in social comparison offline, participants were asked questions such as "how much attention do you pay to how others do things compared to you?" and "do you find you compare yourself to others?" All but one participant admitted they compared themselves frequently offline and that it was just "part of their life." In response to the latter question, Serena gave a typical answer: "A lot. Basically, my whole life. Even if I'm on the subway, I'll look around and be like, 'that person's wearing that. That's interesting' or like,... 'I wished I looked like that. I wish my hair looked like that.'" For other participants like Blair, who was in her first year, she admitted that though she often compares herself to others and "notices how she is different," it has been more frequent since moving from a small town in Ontario to downtown Toronto. This may be an example of how life experiences moderate experiences of comparison. The outlier, Vanessa, was the only participant to say that she does not compare herself to others. In response to paying attention to others, she says, "No. I just don't notice, like ever. I've never done it." Her differing experience not comparing herself will become a point of interest in the discussion. Full and/or 
additional quotes for findings related to offline comparison can be found in Appendix $\mathrm{H}$.

Participants were also explained the difference between directional (upward, downward, and neutral) comparisons and asked if they engaged in one kind more than another. Overwhelmingly, all of the participants engaged in more upward or neutral comparisons. In fact, Eleanor encapsulated the standard response when she admits "Upward comparison is a huge thing. If anything, it probably be neutral or upward, I guess. Well yeah, if I'm looking to compare, it's usually, 'how is this person better than me' in this way, which is my first thought." Jenny went further to offer a sample thought process that sounds similar to the way most participants described their experiences of frequent comparison: "Upward comparison [most], probably. 'They're harder-working than me,' 'they're smarter than me,' or stuff like that. And then there's, like, 'they're prettier than me,' 'they have better hair,' blah, blah, blah. All that kind of stuff, too." While most participants admitted outright or gave examples of how they participate in frequent upward social comparison, our outlier, Vanessa, was adamant that, more than anything, her comparisons are neutral. She answered, "Neutral more often than the others. Yeah. I sort of like, mind my own thing in regards to, like, how I'm going or where everything's at. So I'm 'Hey, I'm doing my thing. You're doing your thing. Whatever.'" Full and/or additional quotes for findings related to directional social comparison can be found in Appendix I.

Not many participants admitted to engaging in downward social comparison. This is potentially due to social desirability bias, which is the tendency for research 
subjects to respond in the way they believe will be favourable to others and will be examined further in the discussion section. For example, though Jenny did not mention making many downward social comparisons, in the observation of her explaining photos on her feed, she was exposed saying, "Personally I would not wear this. That's the first thing that popped into my head, but yeah, I don't know. I'm not a fan of the purse." This is indeed an example of a downward social comparison about her fashion tastes compared to the subject on her screen. For those that did admit to making downward social comparisons, they always exhibited some expression of guilt or explanation attached to it. For example, Lola mentions that downward social comparisons can make her feel good, but also recognized that this might make her "mean." This expression of feeling bad about what she truly experiences came across in other participants as well. Lola says, "If I'm studying with a friend, and I see how unprepared they are...I'd be like, 'Okay, I got a better chance than them.' I'm probably a mean friend for thinking that, but I'm like, 'I think I got this." When trying to describe downward social comparison, many participants similar to Lola would correct themselves when they thought they came across too 'mean.' Overall, participants engaged in more upward social comparisons offline than they did (or admitted to) downward. Full and/or additional quotes for findings related to downward social comparison can be found in Appendix J.

Participants were also asked in what areas of life they compared themselves most. The most prevalent area of comparison that came up at some point for every participant was appearance. After some thought, Lola shows here a very common 
reaction - that of all the areas she compares, it is "especially body image and stuff... with body image, yeah I do, definitely. I look at people and I'm like, 'Hmm. Yeah, that's a good body. That's a goal.' Or definitely, again, makeup or dressing." Similarly, Georgina echoed the sentiment that though she does not compare to everyone, she does, "definitely in the way that I dress... I definitely pay attention to what they're doing. My hair and stuff like that. How I do my makeup. I definitely pay attention to what's going on in the makeup world. Fashion in general I guess." These two experiences were very representative of the whole group. Even for someone who said they compare most in the area of industry involvement as Juliette did, when it came to her observation and what kind of photo she would compare most to, Juliette pulled up a photo of a fit, female rock climber and said, "She has a kind of body that I want." Appearance, in general, whether focused on body, fashion, make-up, or hairstyle, was a major factor and point of comparison for every woman. In general, all but the outlier Vanessa engaged in frequent social comparison, those comparisons were often upward in direction, and many had to do with some kind of appearance-related factors. Full and/or additional quotes for findings related to areas of social comparison can be found in Appendix K. 


\subsection{Social Comparison on Instagram}

$R Q$ \#2: Are young women engaging in social comparison on Instagram? If yes, how? And, what are the differences and similarities of social comparison offline versus online?

To investigate the second research question around understanding how these women experience social comparison on Instagram and how it relates to offline comparison, participants were asked questions such as "how do you feel when using, and after using, Instagram?"'“do you compare yourself on Instagram?" and "do you think it is more, less, or about the same as offline? Why?" Similar to offline experiences of comparison, all participants but one expressed frequent comparison on Instagram. That one will from here on out be referred to as the "outlier." Moreover, all but the outlier suggested comparison was amplified and more frequent on Instagram, and often upward in direction. When asked about offline versus online comparison Georgina explains what most participants shared in some way:

"I feel like it's more comparison online than in person [and] definitely upward...I guess because [everyone] wants to put their best face forward. Anyone can make themselves look good on social media. In person you're seeing who they really are and they're normal people. But on Instagram they look so good or doing all these fun things, but you don't see the rest of their lives that they don't put on social media."

Georgina is expressing a core belief of hers that people's lives are likely worse-off than they appear on the curated Instagram, but yet, she still compares herself more here 
knowing it is not the full truth. Many of the participants expressed similar sentiments to the aforementioned in that it is because people curate only the best photos to be seen - their 'highlight reels,' - that they feel they compare more and more upwardly on Instagram. Vanessa, the outlier, shared a view in line with her offline experiences of comparison. She says, "some of my friends and stuff, they'll compare on social media... But, since I've always just been super neutral about everything I don't tend to, like, fall into that and that kind of thing if that makes sense? So, I think that's really positive for me." Full and/or additional quotes for findings related to the frequency of social comparison on Instagram can be found in Appendix L.

Similar to the offline experiences of these participants, appearance yet again emerged as a point of reference for many of them when discussing comparison on Instagram. In a descriptive and representative statement, Jenny shows her relationship to comparisons of appearance on Instagram. Jenny explains what she compares most: "Looks, online. Of course, because people post pictures, stuff like that. What they're doing, what they're eating, everything, right? So, it makes you compare yourself. Something I'm insecure about is my body and weight and all that, so if I'm seeing someone posting pictures of their food and what they're eating, and it's, like, super healthy and compare to myself, like, I'm eating pizza and all that, right? Kind of just makes me think okay I gotta start eating healthier, blah, blah, all that stuff, right? Or like, I see someone posting a picture of them at the gym, or an "ideal" body shape, et cetera, but it makes me compare myself. Kind of 
makes me feel bad, like, 'oh I need to start going to the gym, I need to start eating healthier.'”

Jenny's quote is important because it demonstrates a kind of inner dialogue showing what it might be like for her to browse through Instagram with appearance at the forefront of her mind-a kind of dialogue that is representative of how many participants tried to describe their experiences to me. Many others echoed the same sentiment that appearance was the area they compared most on Instagram and Eleanor went further to add that this expression of appearance is the purpose of Instagram altogether. She says, "I know that I'm on Instagram to look a certain way while in life I'm just acting in life. I have things to do and life's going on. But there I'm in a bubble where the purpose of it is to be aesthetically pleasing." Through various experiences from multiple participants, partially articulated above, social comparison was both more frequent and more intense on Instagram than it was offline, likely due to the fact that people curate their best selves through the photos on the platform. Full and/or additional quotes for findings related to appearance-related social comparison on Instagram can be found in Appendix M.

\subsection{Consequences of Social Comparison on Instagram}

$R Q$ \#3: What are young women's affective experiences as a result of using

\section{Instagram?}

The third question of this research was to explore the affective experiences of participants after engaging in social comparison on Instagram. The study sought to understand the lived experiences of envy, or the lack thereof, as a result of social 
comparisons. After discussing social comparison on Instagram, participants were provided the definition of envy and asked if they experience envy as a result of using Instagram and what their thought process is like. The majority of participants $(\mathrm{N}=7)$ expressed that they feel envy as a result of using Instagram. While some participants like Eleanor answered without a moment's breath, "Yeah. Yeah. For sure," others explained their experiences in detail. Though Ivy appeared confident when it came to her career, the mere question about envy revealed how her use of Instagram increases levels of envy because she could see her ex-boyfriend's new girlfriend-the one area she did not feel confident. Similar to most other participants, Serena also explained that even with people she truly admires, she still feels envy. She describes, "Yeah, all the power to you. I want to support you. I want to see you go far. I want you to be successful in whatever you're trying to do, [but] there are certain points where I get a little bit jealous of like, 'Oh, I wish I could do that."' Of the three participants who said they don't feel envy, one of them was the consistent outlier. Interestingly, Juliette was another who said she does not feel envy, but admitted she experienced it intensely a few years ago and has since had an "epiphany," improved herself offline, and does not feel it as much anymore. The third, Jenny, also felt that she does not feel envy as much because she more often sees upward social comparisons as "motivating" than she feels "resentment," which will be discussed later. Full and/or additional quotes for findings related to the experiences of envy on Instagram can be found in Appendix $\mathrm{N}$.

In an effort to understand the true consequences of social comparison on Instagram for these participants, I created the possibility to discuss other emotions that 
come out in their experiences. Participants were asked, "Are there any other feelings you experience often as a result of using Instagram?" Many other emotions emerged as a result of social comparison on Instagram. On the darker side of things, participants like Blair went as far as saying they feel, "like I'm trapped almost. If I don't go on and participate and interact, then I'm not part of something socially, I guess." In addition to mentioning a feeling of being "overwhelmed" and feelings of "infatuation," Ivy shared Blair's strong emotions. She says, "I get fed up... I feel like I'm being sucked into something that's so beneath ... not beneath me, but it's like, 'Why do I have to do this?' It's frustrating that I'm still feeding into it. I say this, but I'm still doing it, it's not like I'm changing that." In addition to these two participants, other feelings such as jealousy, sadness, loneliness, a sense of helplessness, and a fear of missing out were mentioned by at least two or more participants.

What emerged as a top shared sentiment was collective frustration with mindless scrolling and time wasted on Instagram, and how that makes the participants feel poorly. Eleanor explains that when she gets the Instagram notification telling her she spent more than one hour on it that day, she feels "like shit" and "disgusting." She felt, like many others, that it was a mindless habit and she sometimes did not know she was doing it. Jenny also had strong feelings about wasting time and a guilt for that that mirrored most participants. She states,

It's a horrible thing. I use it to procrastinate all the time. I'll have, like, homework to do or something and I'll be like, "Okay, let me just go on Instagram really quick," but then I'll just end up spending so much time on it, just scrolling 
through, checking notifications, sending people stuff... I just waste a lot of time...I guess it's kind of "I could have spent my day or my time more wisely doing other things online."

In this one quote, Jenny illustrates for us how the experience of wasting time on Instagram starts, progresses, and eventually ends with a negative judgement of herself. This was a sentiment shared by many participants. Interestingly, even though the outlier was the only one who did not have a negative reaction to the mindlessness, she too noted its presence: "It's something fun to scroll through when I'm bored, absentmindedly scrolling through something." This experience with wasting time and mindlessly comparing on Instagram was prevalent in all subjects, and seen as a source of frustration for nine of the ten. Full and/or additional quotes for findings related to the frustration with the mindlessness on Instagram can be found in Appendix $O$.

Perhaps the most interesting finding of all was that even though the research questions were focused more on exposing social comparison on Instagram and the resulting concerning feelings, all participants also expressed positive feelings as a result of using Instagram. Other feelings that came out were feelings of happiness, inspiration, laughter, motivation, connectedness, and excitement. Blair, Ivy, Serena, and Juliette expressed in almost the same wording that they like how they can connect with friends and family that either live around the world, they have not seen in a long time, or that they did not think they could connect with before (such as photographers). Ivy and Juliette also expressed feeling genuine "excitement" when they see interesting things. Lily shared that, even though she has negative experiences of comparison, she 
often feels positively on Instagram particularly, versus other social media networks. She explains that she usually feels "humour and happiness" on Instagram and is motivated to "strive to do better" when seeing talented people, and furthermore, that if she is "feeling bad," she will "go on Twitter." The striving to do better was expressed as feelings of "motivation" and "inspiration" by Ivy, Juliette, Georgina, and Serena as well. Serena went as far as saying, "Instagram is very much a spiritual place" for her since she can find and learn from people who dedicate their lives to the same kind of spirituality as her. Full and/or additional quotes for findings related to the frustration with the mindlessness on Instagram can be found in Appendix P. Overall, all participants expressed some kind of positive sentiment in relation to how they feel after using Instagram. So, then, why weren't these positive feelings happening throughout all of their Instagram use?

\subsection{Moderators of Social Comparison and Resulting Feelings}

This research was not explicitly focused on factors moderating the intensity of social comparison and therefore it was not a direct research question, however, two moderators emerged enough throughout all interviews that they must be shared. The first moderator and indicator of comparison, both offline and online, was the degree of perceived similarity between the participant and their subject of comparison. The more similar they were, the more likely they were to compare and the more intense the resulting emotions from the comparison. For example, Lily suggested she compared more with people when they were closer in age. When they are closer to her age and successful, she wonders, "Why aren't I like that?" For Ivy and others, comparison was 
amplified or made worse when the subject had similar interests. She explained that when she sees someone as similar to her, she no longer feels "original" and does not like that. Eleanor gave perhaps the most detailed and representative account of this moderator in action, going as far as calling the similarity or "close contact" a "threat." She states,

There was a girl that I used to follow who was very much like me. I've never met her before, she was in my area though... she was someone who I was always like, 'that's someone that I want to be, or to be like... There are a lot of people [on Instagram] that just don't phase me, I'm just like, 'That doesn't affect me, you don't affect me.' And it was mostly just her, I think, because she was so closely in contact to the idea of what I wanted to be like... and she was close to my area too so it felt more so like a threat. Shouldn't have been a threat. Not a threat, but it was a threat to me at the time, for sure.

As shown here by Eleanor, what emerged was that similarity to the participant caused them to compare more and gave the comparison a greater meaning. Full and/or additional quotes for findings related to similarity moderating comparison on Instagram can be found in Appendix Q.

The second, and more prominent, moderator of comparison that emerged was the mental state or offline mood of the participants when they were engaging in comparison. For the sake of this thesis, "offline mood" means the emotions participants were already experiencing on any given day before they opened Instagram. If they were feeling good or had a good and productive day, they were less 
likely to compare-and the results of those comparisons more neutral. If they were already feeling insecure, having a bad day, or being unproductive, they were more likely to compare-the results of those comparisons more frequently upward in direction and with a greater impact on them. Lola, for example, explained how if she had not done physical fitness on a given day and saw fitness model on Instagram, she felt like saying "Screw this, go away with your good body," but if she had participated in physical fitness and was feeling good, then she was happier with herself and more motivated by the models. Similarly, and representative of all participants, Eleanor showed that her opinion of herself on a given day would change the way she interprets comparison. She says,

If I'm busy that day or if I'm out doing something and I'm just scrolling I'll be like, 'Cool. Everyone's doing things. That's cool.' But if I'm at home doing nothing, where I'm at a bad place in my life, or having a mood, then I will definitely be more emotionally affected by certain things. Where if my friends are doing something and I'll be like, 'Oh, that hurts.' I'll be like, This sucks, life's shit.' If I have a breakout [of acne] or something and someone is looking really good and I know I feel sort of dusty today, I'm gonna be like, 'Oh, that's not good either.' If Eleanor had a day full of social interaction, where she felt she looked good, she would be less likely to engage in detrimental upward comparisons with others on Instagram. However, if she had nothing to do or felt "dusty" (slang for unkempt or ugly), she would be more likely to upwardly socially compare herself. All of the participants said in one way or another if they had done something that day to reach 
their goals (like go to the gym or study) they were less likely to engage in upward comparison. Jenny summarized the experience of all participants perfectly when she said her experiences on Instagram "matches [her] mood at the time." If she feels down or poorly towards herself, she engages in "self-loathing," whereas if she is having a good day, she sees "bright colours [and] people smiling," which would make her happy. Full and/or additional quotes for findings related to offline mood moderating comparison on Instagram can be found in Appendix R.

Through this study it became evident that, more than anything else, the previous offline mood of the participants was the greatest moderator and indicator of what their experiences on Instagram and with social comparison would be like. The fact that participants' offline mood at the time altered their experiences of comparison so greatly was one of the most important findings of the study. It is what determined whether they would experience the negative feelings that emerged, such as envy, loneliness, or anger, or if they would experience the positive emotions they also discussed, such as happiness, motivation, or excitement. This will be examined at length in the Discussion section.

\subsection{Unexpected Findings}

\subsubsection{Cognitive dissonance.}

Whether it is feeling one way and acting another, having a gut reaction first and explaining it with reason, or holding two competing beliefs about social comparison on Instagram, all participants but the outlier expressed some kind of cognitive dissonance. Cognitive dissonance can be described as "a feeling of mental discomfort... involving 
conflicting attitudes, beliefs or behaviors" (McLeod, 2018). This discomfort was prevalent all throughout the study. Serena describes a mental dialogue she struggles with that was common to many of the participants when she stated: "It's a battle between being like, 'I feel like shit because of this other person. That other person did nothing to me so why do I feel like shit because this other person.' Then I'm like, 'I feel like shit because of myself.' Then you're like, 'Great. So, I hate myself but at the same time I don't." This back and forth caused a lot of discomfort for participants. Eleanor also showed this discomfort in the ability to hold a competing belief about how Instagram comparison affects her as well as a competing belief about the subjects of her comparison. She says in an emblematic way that, even though she likes following artists, she then feels jealous and "like shit," and then feels even worse for feeling negatively towards the other artists because they are "not doing it intentionally." Though it hurts (a discomfort), Eleanor will still engage because she has explained the discomfort away as 'unintentional' on the part of the subject of comparison.

Eleanor was just one of the nine participants that expressed a similar cognitive dissonance and ability to still use the platform though it causes discomfort. Lola showed what might be the most interesting instance of this. In her observation, she demonstrated a cognitive dissonance, but also how she, like many others, rationalizes what she is seeing. However, even though they rationalize the emotion, it still has a negative impact on them. In observation, Lola points to another woman on Instagram who might compare herself too and says, "She has a nice body. So I would say, 'body goals.' She's fake, obviously, had everything done but it's body goals." Jenny showed 
a similar characteristic reaction when she expressed a distaste and said, "I know that people add filters, I know people pose a certain way so they can make themselves look a certain way, I know things aren't as real online... But then again, of course, there's still that comparison online, all the time." Even though both of these participants logically understand that photos may be edited or bodies may have been altered, the resulting image still affects their levels of comparison and resulting self-regard.

Similarly, Georgina demonstrated that, like many of the participants, she knows certain behaviours are unhealthy, but she continues to engage on Instagram anyways. She explains she finds Instagram positive because it helps her "motivate herself," but at the same time she compares and feels guilty for "being ungrateful for what [she does] have." Again, Georgina showed her initial reaction that was made worse because of the guilt of feeling "ungrateful." In this example, one can start to understand that, aside from the actual areas of comparison, the very acts of comparison in themselves are creating a cognitive dissonance in these participants. That cognitive dissonance is also leading to more frustration, independent of what the initial comparison was. Full and/or additional quotes for findings related to the experiences of cognitive dissonance on Instagram can be found in Appendix S.

This cognitive dissonance in participants was further exposed through a question that asked participants what their advice would be to younger girls using Instagram. In all cases but the outlier, participants gave advice that was the exact opposite of what they themselves are doing. Though Jenny was frustrated with her own time-wasting on Instagram, her advice to younger kids was, "don't waste your 
time. You could be doing better things." Though Georgina is someone who also currently compares her appearance on Instagram, her advice to younger girls was the opposite; to "just accept what you have" and "not everything is what you think it is. [because] a lot of things on Instagram are retouched." Georgina knows that what she is seeing in photos is not always real, but yet, she still compares herself with negative consequences. Though Blair expressed feeling "trapped" and like she was posting out of "social pressure," her advice to younger girls was, "Don't get sucked into it. Don't make it your main thing that you go on every day." The fact that most of the participants' advice, or what they see as the right way to do it, is the exact opposite of what they are actually doing demonstrates an active cognitive dissonance in their competing beliefs and actions. The outlier was the only one whose advice seemed to line up with her actions. She wanted to remind younger girls that people are "posting their best selves" and if you "post your best self, someone else is probably gonna look at it and feel the exact same way you do.... So, it's like, whatever." For the outlier, it actually does seem to be as inconsequential as "whatever."

\subsubsection{Social pressure.}

Between the negative emotions of envy, insecurity, being "fed up" or "trapped" paired with the stress and discomfort of the cognitive dissonance the whole experience of using Instagram seems to be causing, my next question became about why participants were still engaging in this behaviour when it was causing them distress when it was not beneficial. Though the focus of this research was not exploring why people engage in potentially risky behaviours, a theme that emerged in participant 
experiences might start providing an answer for this as well as guide future research. In an effort to explain their harmful behaviours or experiences to me, many of the participants described a kind of "social pressure" or "social norm" that keeps them engaging in harmful behaviours such as frequent upward social comparison or social comparison on Instagram versus just logging off.

After revealing that she follows people she does not know or like, Blair gives us an example of this shared sentiment when she says, "I feel that pressure to stay connected with people in that way, but it's not really a genuine connection... I feel like it's just a social game, that if you're not in it, then you're kind of out of the loop." She goes further to explain, "because they followed me initially... I feel pressure to follow people back if they're going to follow me, even though I don't know them." Similarly, in the below live exchange between Georgina and I during her observation, one can see in real-time the way this pressure plays out in how many participants use Instagram. Looking at a photo of a man and woman in a relationship, I asked her "who are they?" Georgina answers, "I don't know him. We went to high school.. but I never talk to him." I probe, "Why do you follow him?" Georgina explains, "I don't know. We just follow each other. It's kind of a mutual thing. People, you know of each other, but you don't talk to each other, I guess. You just follow each other." Similar to Blair and Georgina, many others also mentioned feeling a pressure to post, to like people's photos, to buy the things they see, to "remind people you're still alive," and a pressure to post and dress in a certain way. Full and/or additional quotes for findings related to social pressure on Instagram can be found in Appendix T. 
This pressure to compare oneself to others, which has been shown to translate over to experiences on Instagram, comes not just from peers, but some participants shared that it went back to childhood and family pressure as well. At least three participants mentioned family pressure with regards to comparison. As a way to explain why she believed she compares herself a lot, Jenny mentioned that her parents often compared her to her sisters and cousins growing up while Georgina admitted that she grew up with a mother that worked in the beauty industry and always emphasized that she needed to "look her best." Lola also believed her experiences of frequent comparison came from childhood and added a cultural layer suggesting that being from a South Asian family came with more "care about their name and reputation" and therefore more judgement on her. All of these experiences with family/cultural pressure suggest that experiences of comparison could be socialized from a young age. Though not a main focus of this study, these sentiments may open up questions for future research that could explore the connection between family dynamics/values and social comparison. 


\section{Discussion}

The present study comprises an investigation into how young women experience social comparison offline, how that translates onto Instagram experiences, and the resulting feelings from those experiences. In an effort to introduce the subjects' voices into the research, and thus a more nuanced understanding of social comparison experiences on Instagram, I conducted a series of 20 semi-structured interviews with 10 participants, 30 minutes each, and approximately one month apart. This method was strategically chosen because on top of allowing participants to explain their experiences in their own words, the semi-structured nature allowed for a more free-flowing and natural conversation, which elicited more open responses from participants. The importance of this semi-structured nature was highlighted when Blair said,

I like what you're doing... You made this interview very easy. I didn't feel intimidated at all. Last time I participated in this study was for psychology, and I was just so intimidated because they're like, very official. I wasn't sure what to expect walking into here, but it was, it was good. And I feel like this topic, I could talk about it for hours, honestly.

The method was perhaps the most important element of this study and allowed for the nuances in the findings to become clear.

\subsection{Relationship to Research Questions}

Findings in previous research regarding the relationship between time spent on social media and a decline in well-being have been largely inconsistent. However, 
when social comparison and/or the results of that comparison, were introduced as mediating variables, there was often a relationship that suggested social comparison was the real cause of a decline in mental well-being. Because of this, the first goal of this study was to learn about participants' experiences of social comparison offline. The findings suggest that if participants compared themselves offline, they were likely to also compare themselves online as well. In this respect, the findings of this study were in line with what I believed would be the case. All but one subject (the outlier) indicated they compare themselves often offline and all but the same subject indicated they compare themselves frequently online as well. The outlier is not the exception to the rule, but rather supports it more so-she did not compare much offline, and similarly, did not compare much online.

The second goal of the study was to understand not just if, but how social comparison was experienced on Instagram. I speculated that social comparison would be more frequent and have more consequential repercussions when happening on Instagram. This speculation was proven correct. All subjects but the same outlier felt they engaged in more social comparison on Instagram and further, that they particularly engaged in more upward social comparison on Instagram. Many of the subjects themselves theorized, as I believe, that this happens because you are seeing only people's best and brightest moments on Instagram and that they are likely retouched and often literally unreal. The outlier once again was the only one to believe she compared herself "about the same" as offline, and that those comparisons remained fairly neutral. Though she is only one person, this might suggest that the 
frequency of offline social comparison is positively correlated with the frequency of online social comparison. If you engage in social comparison frequently offline, you will engage frequently, and perhaps more, online. If you do not engage frequently offline, you will likely remain neutral online.

Finally, the third goal of this study was to investigate how subjects interpreted their experiences on Instagram and what feelings they experienced as a result. In line with the previous research, I speculated that frequent social comparison on Instagram would cause subjects to feel envy and a host of other feelings pending how they spent that time on Instagram and how they were feeling going into it. This was perhaps the most important finding in this study. Seven of ten participants reported experiencing envy and all but the outlier reported feeling many other negative feelings as well such as loneliness, anger, trapped, etc. The three that did not experience envy (including the outlier) reported that upward social comparison on Instagram often made them feel motivated to achieve what they perceived as better. Two of those three participants that felt this way also mentioned explicitly that they had been feeling good offline at the time of the research. The outlier is interesting because she too proves the finding even more. When asked why she believes she does not compare herself, she said, "I'm content with me." This suggests that her contentment, and even a perceived confidence about who she was, prevented her from engaging in frequent social comparison, and that this confidence stayed with her when she went online. Juliette too was one of the ones who does not feel envy as much today, but admitted she used to and "had to figure [herself] out offline first." She indicated to me that, since her 
epiphany, she too had to learn to be confident with herself. These findings might also suggest that how you feel about yourself offline is a greater indicator of a negative reaction to social comparison on Instagram. This particular finding was also underscored by the fact that all subjects also reported having positive experiences and emotions after using Instagram as well - feelings such as inspiration, motivation, happiness, excitement, etc. The semi-structured interviews that allowed subjects to explain themselves showed that no one subject had only negative or positive comparison experiences, but that both can happen simultaneously and change day-to-day, making "time on social media" an inadequate predictor of well-being.

\subsection{Relationship to Social Comparison Theory}

The findings of this study, in many ways, could have been predicted by social comparison theory. The main premise of social comparison theory is that people compare themselves as a means of understanding their identity and where they fall in the social order. All subjects displayed a tendency to compare themselves to others. Even though the outlier said she did not engage in much social comparison, the very fact that she references friends who look at things differently or in a more detrimental way was an 'in-real-time' example of her engaging in neutral and downward social comparisons with her friends as a way to explain that, in her view of her identity, she does not compare often. In other words, she was actively comparing to suggest she does not compare, which is clearly false.

This study expands our understanding of the theory by applying it to the world of Instagram specifically, thus extending the scope of social comparison theory beyond 
the field of psychology and applying it to the world of mass-communications. This may provide us with a clearer understanding of how social comparison occurs, where, and the consequences of it on those making the comparison. Furthermore, this study invites the voices of those doing the comparing and provides intimate insight into how people describe, and make meaning of, the comparisons they make. The findings of this study also suggests that the very act of comparing in itself has an impact on people regardless of the direction. Ultimately, my research suggests that social comparison theory is very relevant in the social media context. Social media, and Instagram in our case, is a space ripe for upward social comparisons to occur since people are sharing their mediated highlight reels. My findings suggest upward social comparison is happening more online than offline, and with this in mind, we start to understand more about the implications of social media use on us as a whole.

Social comparison theory is said to be motivated by the pursuit of self-enhancement, self-verification, and self-assessment. The participants provided examples for all three motivations. Lola, for example, admitted that when her friends are unprepared for a test she is prepared for, that the downward social comparison makes her feel better. This is self-enhancement. Ivy admitted that she sees herself as "original" in her style and feels she is doing well in her career. She shared that she uses social comparison with peers to reaffirm both of these things. This is self-verification. Participants like Blair admitted that she feels good when her photos get a lot of likes. To her, it affirms that others also thought this was a nice picture, pose, outfit, etc. This is self-assessment. With the outlier, one might argue that because she felt "content" 
with herself, that she did not have as much of a desire to get an accurate read of herself. She already thought she had one and therefore did not need to compare as much.

Social comparison theory also argues that the tendency to compare with someone else decreases as the differences between the subjects increase. Worded differently, this also means that the more similar you are to a subject, the more likely you are to compare yourselves to them. This may be because the subject will give you the most accurate read of yourself. This too was proven true in our findings. What emerged as one of the indicators and moderators of social comparison in this study was in fact perceived similarity between participants and their subjects of comparison. They admitted that if someone was closer in age, in the same academic program, in a similar professional industry, the same gender, and/or had similar interests, that they would be more likely to compare, and the results of that comparison would be more impactful. For instance, Ivy wanted to follow people who had similar interests and success in her industry, but she preferred they were older and much more successful because this would make her feel motivated towards where she wants to go, but if they were close to her age or stage of life as a student, she turned more towards jealousy. If one wanted to compare themselves less than, they might consider following people who are very different from them, or if they are similar in things like interests, they should be different in other areas like age.

Social comparison theory developed to include directional comparison otherwise known as upward, downward, and neutral comparisons. Frequent upward 
social comparisons have been linked to a decline in well-being (Jin et al., 2019; Ho et al., 2016), which was clear in the findings. All but one of the participants expressed frequent upward social comparison and negative feelings as a result. However, the theory also suggests that social comparison can be used to make you feel better. For example, research (Collins, 1989; Taylor \& Lobel, 1996) previously showed that, though upward social comparison can be problematic, if done in the right context, it can also be motivating. More recent research concerning social comparison theory and social media use also found the possibility for positive experiences after upward social comparison as well (De Vries et al., 2018; Weinstein, 2018). This too was proven true by the fact that all participants experienced positive feelings as a result of comparing on Instagram and at least five of them mentioned feeling "inspired" and "motivated" specifically. What this study proved to be the biggest indicator of whether or not someone crossed the line from healthy to unhealthy upward social comparison was their offline affect at the time of use. This study showed evidence that for all subjects, the results of social comparison were largely dependent on how they were feeling about themselves that day. If they were having a good day and did things to achieve their goals, upward comparisons did not affect them as much. The opposite was true as well.

Scholars such as Wills (1981), Gibbons (1986), and Stewart, et al. (2012) all found that downward social comparison could improve someone's subjective well-being as well. However, my present research showed that most participants either did not engage in frequent downward social comparison or did not admit it. For those 
that did, they also expressed a constant guilt and shame for thinking that about another person. Though social desirability bias may prevent them from disclosing when they look 'down' on someone else, there were also many instances given of inner dialogues these participants have shaming themselves for that behaviour. If someone was feeling bad due to social comparison, the theory then might prescribe they go engage in downward social comparison as a way to make themselves feel better. However, the findings of this study suggest that would not work because the guilt and shame would actually make them feel worse. This is the only area of the theory that the findings of this study challenge, and only ever so slightly. The findings demonstrate that each of the directional comparisons comes with their own set of positive and negative aspects that are moderated by offline affect.

Finally, social comparison theory has previously been used as a lens to explore the connection between social comparison and well-being. It was previously found that frequent social comparison is linked to a decline in well-being and self-regard, and especially, it has been linked with envy as seen in the literature review. Considering the theory, it should not matter then where this comparison takes place. Whether as a result of offline or online experiences, the results are similar. The findings of this study show that all but one woman engaged in frequent social comparison offline and online, and that for seven of the ten, they did indeed experience envy as a result of this. However, pending their offline affect, they could also experience a whole host of other emotions as well. This is an important piece for the future of research in this area, to be discussed below. 


\subsection{Relationship to Literature}

In the literature review section of this thesis, it was shown that there were different and sometimes opposite findings emerging in the research exploring social media's relationship to mental well-being. Much of the research so far has explored how time spent on social media correlates with declines in well-being, including depression or anxiety. While some scholars found a strong correlation between the two (Kross et al., 2013; Pantic et al., 2012; Woods \& Scott, 2016), others found no correlation at all (Thorsteinsson \& Davey, 2014; Davila et al., 2012; Steers et al., 2014; Jelenchick et al., 2016). What seemed to remain constant and more prominent is that when mediators such as 'social comparison' were introduced between social media use and depression, there is always a negative correlation. In fact, other research found that if these mediators were not present, subjects showed improved mental health after using social media. This suggests that social media alone does not cause depression, but rather the acts of comparison, or negative feelings as a result of that comparison, cause depression and just happen to be accentuated by social media such as (and especially) Instagram. The present study was conducted in an effort to help clear up some of those inconsistencies and explain why they exist in the first place by focusing on the experiences of social comparison during the time spent on Instagram. The methodology was designed to expose new intricacies that might not be clear in the quantitative research that has been prevalent to date in this area.

To begin, the findings of this study suggest that 'time spent on social media' is in itself not a strong predictor of a decline in mental well-being. The findings show that 
research that previously investigated the mediating variables between time spent on social media and declining mental health was moving in the right direction. Participants of previous studies did indeed describe experiences such as engaging in social comparison (Steers et al., 2014; Wanget al., 2017; Vogel et al., 2014; Nesi \& Prinstein, 2015; Chae, 2018), feeling envy (Tandoc et al, 2015; Jin \& Muqaddam, 2018; Krasnova, et al., 2013; Li, 2019), having lowered self-esteem (Chua \& Chang, 2015; Wang et al., 2017), and feeling lonely (Ingvadóttir, 2014) after using social media.

The fact that all participants in this study also shared positive experiences on Instagram and times when it seemingly improved their mental well-being (by being made to feel happy or inspired, for example) shows that social media can be a beneficial mental health experience as well. This falls in line with the few scholars who admitted that when mediators such as comparison or envy were not present in their subjects, social media could and did have a positive effect (Thorsteinsson \& Davey, 2014; Valkenburg et al., 2006; Weinstein, 2018; Ellison, et al., 2007; De Vries et al., 2018).

The research that found the most similar findings to this study were De Vries et al. and Weinstein's 2018 studies. De Vries et al.'s experiment showed offline affect to be the biggest predictor of how their participants reacted to positive, negative, and neutral posts in their experiment. They also found that if users had a positive affect, they tended to view others' positive social media posts through an emotional contagion lens, which meant they took on the joy of the poster, which of course improved their mood. This is similar to the participants in our study who also felt 
happier for their subjects of comparison if they were feeling good about themselves.

Weinstein (2018) also found after in-depth interviews, that if participants were not experiencing feelings such as envy, they too experienced benefits such as: 1) relational interactions contributing to closeness; 2) self-expression facilitating affirmation of themselves; 3) interest-driven exploration to gain inspiration, and; 4) browsing that could lead to entertainment and admiration. The findings in the present study are most similar to Weinstein's findings. As Weinstein suggested, all of the four categories of benefits could also be the same categories for negative experiences. Through the interviews, Weinstein's participants, as in the present study, expressed both positive and negative consequences of using social media, which suggests something else is at play to make a good experience go poorly. Interestingly, both of the aforementioned studies included a qualitative element in their research design, which I believe allowed for a more nuanced story to be told about people's experiences on social media and may contribute to why this study has found similar results. All findings put together might suggest that we need to start flipping the variables, and instead of studying how social media changes people's moods, start studying how people's mood affects their social media use, an idea that will be discussed further below.

\subsection{Implications}

The findings of this study tell us just how important a factor social comparison is in determining how people feel as a result of using Instagram. More importantly, the findings show that offline affect and self-esteem are more important in determining participants' subjective well-being after using Instagram than simply time on the 
platforms. Semi-structured interviews proved to be a good choice because it allowed the participants to explain themselves and provide examples of how they interpreted everyday experiences, which ultimately revealed that though they did indeed engage in social comparison, the direction of those comparisons was caused by something else: how they felt about themselves offline. One of the main motivators of this research was to help shed light on the connection between Instagram use and declining mental health so that we may ultimately prescribe better solutions. The findings of this study might suggest that in order to help people be well after using social media, we actually need to focus not on social media but more on boosting overall self-esteem and confidence in people before they use it.

What became clear through this research was that many of the participants seem to have contingent self-esteem, which is when self-esteem is contingent on social comparisons and the external opinions of others. Those whose "self-esteem is more contingent are more likely to feel good about themselves only when they receive approval, praise, or success in terms of societal standards, or self-set objective goals" (Kang, 2019, pp.2). Many participants in this study suggested that social comparison, as well as the likes they get on social media, can make them feel better about themselves. The fact that $100 \%$ of participants also got on Instagram between ages 11-13 (before they are allowed according to Instagram's policies) means that from an early age and through puberty, they may have been slowly conditioning their self-esteem to respond to the constant external feedback cycles social media provides. 
Later adding to the research on contingent self-esteem came an exploration into what the main contingencies were affecting self-esteem for post-secondary students (Crocker \& Wolfe, 2001; Crocker \& Knight, 2005). Among others, Crocker's research found that some of the main domains for those contingencies of self-worth for postsecondary students were academic performance, appearance, and family love (2001). Most participants in the present study addressed all three of these common contingencies of self-worth as areas they compare themselves, and most especially in the appearance domain. Appearance was brought up by all participants as an area they compare themselves frequently, and moreso on Instagram than offline. Within the appearance domain, they especially referenced their bodies and the "thin ideal" (Kathryn, Charanasomboon, Brown, Hiltunen, 2003) as something they desire. The thin ideal is the classifying of a desirable woman's body as being thin with a small waist and not much body fat. This ideal has been propelled by media and other socializing agents for years and has been believed by many women to be "valuable" and perceived to be linked to confidence, happiness, and romantic success (Tiggemann, Polivy, \& Hargreaves, 2009). Previous research has also shown that internalization of the thin ideal, or the "degree to which an individual has accepted societal values of thinness and applies these values to herself" (Juarascio, Forman, Timko, Herbert, Butryn, \& Lowe, 2001, pp. 207) affects the degree to which they will allow comparing themselves in that area to alter their self-esteem. Though the thin ideal was made prevalent by all participants, an internalized thin ideal paired with the 'family love' domain were present in both participants who mentioned that this thin ideal was very 
important to their parents growing up and therefore an area they compare themselves more in.

Unfortunately, the danger of contingent self-esteem is that "because such things as success, recognition, and approval from others are not everlasting, self-esteem dependent on those factors likely becomes unstable and fragile" (Kang , 2019, pp.2). Social media-Instagram as the perfect example-provides a space where likes, comments, shares, and messages, can become a constant stream of the kind of external feedback that feeds contingent self-esteem. However, like we saw with some of the participants in this study, if that feedback stops (eg. if they don't get as many likes on one photo), or if you compare yourself to others and deem yourself worse off, the self-esteem dissipates leaving the comparer in a depressed position. If social media is breeding this kind of self-esteem in kids as young as 11 years old, a potential implication of this research may be an encouragement for future scholarship to explore how contingent self-esteem and contingencies of self-worth (especially in the appearance and thin ideal domain) are formed in adolescents who use social media.

Because contingent self-esteem relies on others' feedback, and others are not always there nor always provide positive feedback, this kind of self-esteem is flimsy in nature and may be a reason why social grooming emerged as a way to maintain relationships. Social grooming is "the social function of engaging in interactions to manage and form social ties" (Lin, 2019, pp. 91). In the wild, social grooming may consist of more literal grooming such as chimpanzees who clean each other while social grooming between humans may consist of maintaining one's appearance so as 
to remain socially acceptable. Scholars have written about how social media is the place for modern social grooming to take place in the form of liking others' posts, following people, writing on their walls, privately messaging folks, or sharing birthday messages for others on your stories (Donath, 2008; Lin, 2019). It is believed that humans and other primates are partly motivated by "reciprocity" (Ventura, Majolo, Koyama, Hardie, \& Schino, 2006) to engage in social grooming, or in other words, that "they 'expect' some benefit in return from those that they groom and/or the larger population" (Krueger \& Jin, 2008). An unexpected finding in this research was just how prevalent social grooming, and the pressure to do so, was for the participants. For instance, many participants felt they had to follow people back simply because that person followed them. They felt a pressure to post about friends on their birthdays because those friends had done it for them. They felt a pressure to like and comment on all of their friends' new posts so that it would be 'reciprocated' when they later posted a photo of their own. When asking one participant during observation why she was speedily liking every single photo without looking at them, she said she did not know why and it was "just something you do" so as to indicate it was a standard social practice. For someone with contingent self-esteem, it may feel like social grooming is especially necessary as a way to ensure you get that feedback you so desire. I would hypothesize that the greater one's self-esteem is contingent on others, the more pressure they feel to engage in social grooming strategies and further, would be more affected if there was no reciprocation. If we believe that social media can condition contingent self-esteem, that that kind of self-esteem may lead to a feeling of pressure 
to engage in social grooming as well as a potential downturn in well-being if it is not reciprocated. If we believe all of that to be true, it would be even more worth it for future research to explore the connections between contingent self-esteem and social grooming on social media so that, again, we can diagnose the root cause of issues.

Another unexpected finding in this research was the prevalence and consequences of cognitive dissonance on the subjects. Though I speculated that the results of a social comparison online would lead to a decline in well-being, it was more the subject of comparison that I was focused on. However, through this qualitative research, the very act of comparing in itself and knowing they were doing it seemed to make many participants feel even worse. For example, many participants admitted to feeling guilty if they made an upward comparison to someone who was doing positive things. This guilt was intensified for downward comparisons, though that may be explained by social desirability bias (the tendency for people to respond in the way they believe will be favourable to others). Participants identified an almost cyclical motion of: feeling bad to begin with and therefore comparing themselves to others, which then leads to them feeling bad about having made the comparison at all, and then starting the cycle over again. Though it still seems that the subjects and areas of comparison (eg. comparing one's body to a fitness influencer) seem to affect the participants more than the guilt of having made the comparison at all, future research could look deeper at people's reactions to the act of comparing as it relates to social media, and not just the results of the comparisons made there. 
Perhaps the most important implication of this research in conjunction with all of the research that came before it, is that social media is a risky behaviour. In psychology, a risky/risk behaviour is fairly simply a behaviour that may expose you to potential harm. The degree and intensity of that harm is not always known to the subject indulging in the risky behaviour and precautions may or may not be taken to reduce the risk of harm. Other familar risky behaviours include drinking alcohol, consuming cannabis and other drugs, unprotected sex, or speeding when driving. It is evident through the present research that there are inarguable risks to participating actively on social media and especially Instagram. As was shown in the present and previous research, potential risks of engaging actively on Instagram include feeling envy, guilt, depression, loneliness, a decline in affective well-being, burnout, addiction, and others. The risks we have not covered in this thesis may also include harassment and cyberbullying, seeing traumatic imagery, or even related physical issues such as carpal tunnel from smartphone use (Korpinen, Pääkkönen \& Gobba, 2018). A strong implication from this research is that research, policies, and education about helping people experience social media positively should be treated similar to these other risky behaviours if we ever want to curb these negative consequences we have been seeing.

If we decide to start calling and treating social media like the risky behaviour it is, we could look to the handling of other risky behaviours as a model forward. For example, similar to other risky behaviours, we would need to start with awareness and making sure people understand the risks of partaking. However, as with other risky behaviours like alcohol and sex, someone's mood and/or social pressure can drive 
people to indulge in the risky behaviour regardless of the risks. If we want to make it so that people can reduce the risk and engage on social media in a healthy way, we must start educating the masses on what we know and focus on the offline skills that help people navigate other risky behaviours.

In the wake of these findings paired with previous research, the practical implications of this research would be that to have a real impact on people like the participants of this study and make their online experiences more positive, they must first endeavour to improve themselves offline. For one, helping [young] people move from contingent to non-contingent self-esteem is critical. In addition, to make it so that they thrive no matter what they experience on social media, I recommend people build soft skills such as: inner confidence; self-awareness, so they know when they are in moods that will not pair well with social media; mindfulness, so they never find themselves frustrated that they have wasted an hour and do not remember what they saw; time-management, so they can get a sense of how much they are doing the aforementioned; and resilience, so that no matter what you see on your feed, they are able to bounce back quickly and thrive. This research suggests that if people build up those skills, they too would have an experience closer to the outlier-more full of positive feelings such community, connection, motivation, humour, and more.

\subsection{Limitations \& Future Research}

This research is not without its limitations. One limitation is that I studied only people who actively post on Instagram, meaning they are content creators. I did not study "lurkers" or people who only consume others' content. Future research might 
explore if the experiences of comparison are similar or different depending on whether people create content or not. The most obvious limitation is the sample size of the group and therefore all of the diverse experiences one cannot see with only 10 people. With 10 participants, it is harder to generalize that this is the experience of all people/women/young people using Instagram. We considered recruiting more people, but after 10 interviews I found theoretical saturation. The overwhelming similarities in the experiences of these 10 may indicate one might uncover similar findings in a broader sample. The present study, for now, should be treated as a snippet into what could be uncovered through more qualitative research in this area. On this note, future research should include a larger and more diverse group of people. The experiences of people of colour, queer folks, and/or disabled individuals would be of interest to future research since it could go either way and make the findings more complex.

Another potential limitation was that the subjects of this research are all between 18-24 and considered young adults. It could be argued that, regardless of social media, young people are already at a phase of life where they compare themselves as a means of identity construction and therefore compare themselves more on Instagram as well. At the same time, this would also underscore why understanding this connection is vital for the well-being of young people today and in the future. It would be beneficial for future research to explore how instances of comparison on social media differ in various age groups. However, the research here will be most applicable once social media has been around long enough for people of all ages to have grown through puberty with it as well as older adulthood. 
In further limitations, the method of qualitative interviews proved to be enlightening though we know that social desirability bias will always be somewhat present when there is a known researcher present. Perhaps future research might explore in a two-part study how subjects' answers do or do not change across methodology and put them together to create a fuller picture.

In many other published studies, scholars admitted that a limitation of their research was that they could not confirm direction of their findings (Appel et al.,2015; Hawi and Samaha, 2017; Chua and Chang, 2015; Ingvadóttir, 2014)-was it that depressed, low self-esteem, and lonely people use social media more or the other way around? I believe the present study suggests that more emphasis should be placed on how people are feeling offline before they get on social media. I strongly recommend future research changes the direction of the variables in order to clear up the inconsistencies. For example, instead of measuring how people feel as a result of using social media, future research should consider those that do and do not have high/low or contingent/non-contingent self-esteem and the differences between their social media experiences. In this research, we might consider the outlier of this study. She was someone who appeared to have self-esteem that was less concerned with others. Future research might endeavour to explore how and why she, and those like her, felt content with herself, and more importantly, how to replicate that for others. 


\section{Conclusion}

As social media proliferates society more and more every day, it is clear to see that social media, and particularly Instagram's relationship to society and mental health, is profound. Though when one looks to the research for an answer, they will find studies on all sides of the equation. However, most research with the present study included, found evidence to suggest that social media is not the main cause for concern, but rather that offline feelings and mediators like envy, comparison, or self-esteem, seem to alter mental well-being more. In order to help clear up the inconsistencies, the present research endeavoured to introduce new qualitative methodology to this area in order to illuminate a clearer picture of what is going on, and more importantly, how practitioners can then work to help solve the real cause for concern in people's declining well-being as it relates to social media. In this case, young women's experiences of social comparison on Instagram were explored.

It was found that participants do indeed compare themselves often offline and that is amplified on Instagram. Furthermore, it was clear that as a result of Instagram use and the social comparisons made within, participants can feel worse-off experiencing emotions such as envy, loneliness, guilt, etc. Between the present research and all before it, it is clear that there are many risks to using social media and that perhaps we should consider it a risky behaviour in the same vein as drugs, alcohol, or unprotected sex. That being said, all participants also described positive experiences on Instagram as well. The most important finding was that all of the participants indicated that how they felt about themselves offline going into their social 
media use was of grave importance to their experiences of comparison and the resulting feelings. If we consider social media use like other risky behaviours, such as alcohol, it would be extremely valuable for future research to flip the script, and instead of studying the effects of alcohol or social media, studying why people turn to these behaviours in the first place. Afterwards, practitioners should focus on the offline soft skills such as self-esteem, self-awareness, resilience, and mindfulness so that no matter what people face online, they can handle it. For those working in healthcare, this research should enlighten a potential reason for declines in well-being. For those in education, this research should illuminate areas of development that might be most beneficial for people in the long run. For social media consumers, this research should demonstrate the risks of partaking and make you consider how you will take precautions in an effort to be well. Ultimately, a deeper understanding of how the experiences of young people on social media affects their personality is important and increasingly urgent. My goal was that this research would advance the conversation in this area and I look forward to where we go from here. 


\section{Appendices}

\section{Appendix A.}

\section{Recruitment email to program coordinators.}

Hi Everyone,

I'm reaching out because I'm hoping you'll forward this opportunity to your students. I no longer work as a Digital Marketing Specialist in Student Affairs Special Projects, but I am still working with them and RU Student Life to execute my graduate research regarding social media and mental health, and more particularly the experiences of comparison and envy on Instagram (the most popular social network with our students).

I am recruiting students for my interview-based study (compensation for students included), and I'm hoping you will forward the below email to them with the attached poster.

If you are not the person who should be receiving this kind of email for your program, please let us know and we will update your name on our list.

\section{YOUNG WOMEN NEEDED FOR VOLUNTARY INSTAGRAM STUDY}

\section{WHY:}

For your time, you will be given $\$ 20$ while contributing to a greater understanding of how social media use truly affects us.

\section{WHAT:}

We are looking into the acts of comparison and feelings of envy as a result of Instagram use with a goal of understanding more about social media's effect on mental health. Study Title: \#NeverEnough: Comparison \& Envy on Instagram.

\section{HOW:}

In this study, you will be required to give two 30-minute, confidential interviews on separate days about your Instagram use and resulting feelings. These will take place at Ryerson.

\section{WHO:}

- You identify as a woman 
- You are between the ages of 18-24 as of October 1, 2018

- You speak and understand fluent English

- You are a full-time undergraduate student at Ryerson University in the 2018-2019 academic year

- You have an active personal Instagram account

- Your Instagram account is set to public

- You check your personal Instagram feed at least once per day

- You post on your personal Instagram account at least once every 2 weeks

\section{NEXT STEPS:}

If you meet the above criteria and are interested in participating, please fill out the form at:

\section{http://bit.ly/RUInstagramStudy}

Cheers,

Bailey

\section{[ATTACHMENT]}

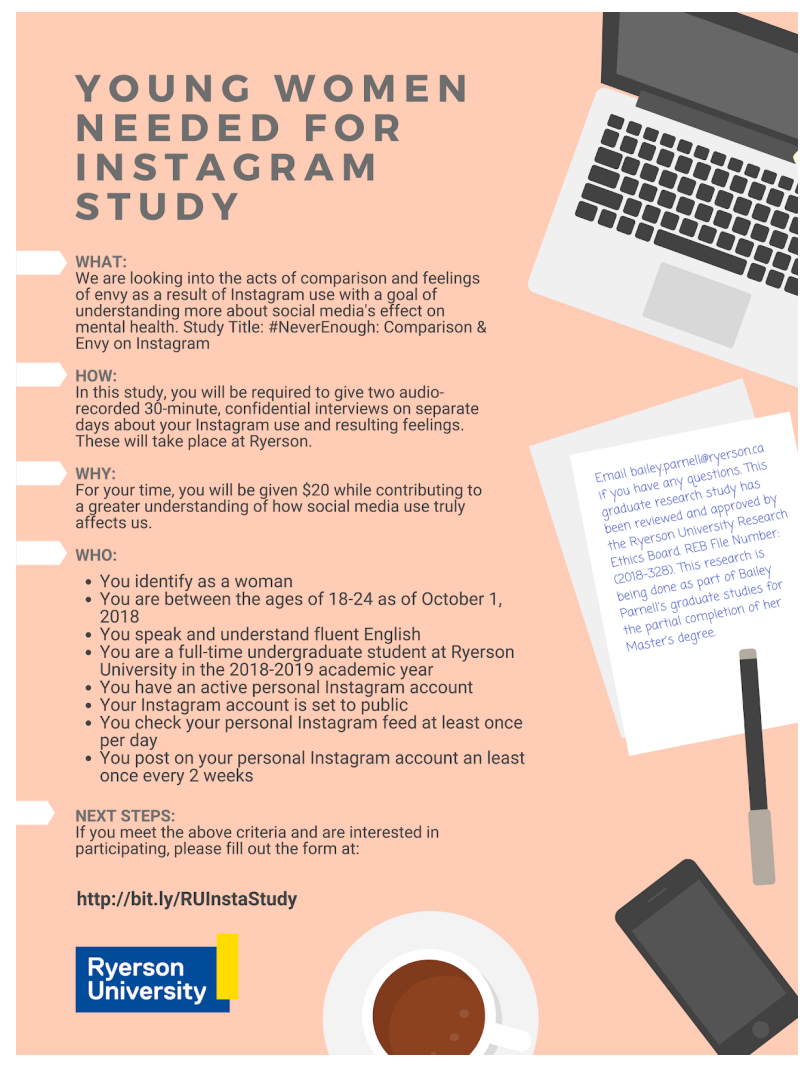




\section{Appendix B.}

Recruitment copy/social media posts for RU Student Life.

\section{Mailchimp Email Newsletter}

[This is separate from weekly newsletter - its own post. Pulling inspiration from the below RUSL link and my own approved recruitment materials. Of course, a giant box like you have with the link is best.

https://mailchi.mp/ryerson/participants-needed-for-research-study?e=6e41188e90]

\section{Subject:}

Young Women Needed for Ryerson Instagram Study

\section{Body:}

[Insert Image: https://goo.gl/o41F21]

\section{YOUNG WOMEN NEEDED FOR VOLUNTARY INSTAGRAM STUDY}

\section{WHY:}

For your time, you will be given $\$ 20$ while contributing to a greater understanding of how social media use truly affects us.

\section{WHAT:}

We are looking into the acts of comparison and feelings of envy as a result of Instagram use with a goal of understanding more about social media's effect on mental health. Study Title: \#NeverEnough: Comparison \& Envy on Instagram.

\section{HOW:}

In this study, you will be required to give two 30-minute, confidential interviews on separate days about your Instagram use and resulting feelings. These will take place at Ryerson.

\section{WHO:}

- You identify as a woman

- You are between the ages of 18-24 as of October 1, 2018

- You speak and understand fluent English 
- You are a full-time undergraduate student at Ryerson University in the 2018-2019 academic year

- You have an active personal Instagram account

- Your Instagram account is set to public

- You check your personal Instagram feed at least once per day

- You post on your personal Instagram account at least once every 2 weeks

\section{NEXT STEPS:}

If you meet the above criteria and are interested in participating, please fill out the form at:

\section{http://bit.ly/RUInstagramStudy}

Email bailey.parnell@ryerson.ca if you have any questions. This graduate research study has been reviewed and approved by the Ryerson University Research Ethics Board. REB File Number: (2018-328). This research is being done as part of Bailey Parnell's graduate studies for the partial completion of her Master's degree.

\section{Instagram Stories/Snapchat}

[The 3 graphics (in folder above) have all relevant information on them. When sharing all three, please include the following link. Really, I don't care if they choose to swipe up after the first graphic or third, so the link can be included on all. http://bit.ly/RUInstagramStudy. If you want to tag me invisibly @BaileyParnell (as in making it small and the same colour as the background, then I can easily share it to my account too!]

\section{Facebook Posts}

\section{Option 1}

We are looking for female-identified Ryerson students to take part in a research study about comparison and envy on Instagram. Participants will receive $\$ 20$ for their time and will contribute to understanding how social media affects our mental health.

To see if you're eligible and to sign up, please fill out the short form at: http://bit.ly/RUInstagramStudy. 
\#TakeCareRU \#SafeSocial

[graphic 1 from folder]

\section{Option 2}

Do you use Instagram every day? You might be eligible to participate in our research study looking into the effects of Instagram comparison on our mental health. Participants will receive $\$ 20$ for their time and will contribute to a greater understanding in this area.

To see if you're eligible and to sign up, please fill out the short form at: http://bit.ly/RUInstagramStudy.

\#TakeCareRU \#SafeSocial

[graphic 1 or 2 from folder]

\section{Twitter Posts}

Feel free to tag me in the photos on twitter @Baileyparnell and I can repost.

\section{Option 1}

We are looking for Ryerson students to take part in a study about comparison/envy on Instagram. Participants receive $\$ 20$ for time \& contribute to understanding social media \& mental health. For eligibility \& to sign up, go here: http://bit.ly/RUInstagramStudy. \#TakeCareRU \#SafeSocial

[Insert graphic 1 from folder]

\section{Option 2}

Do you use Instagram every day? You may be able to take part in a study about comparison/envy on Instagram. Participants receive $\$ 20$ for time \& contribute to understanding social media \& mental health. For eligibility \& to sign-up:

http://bit.ly/RUInstagramStudy. \#TakeCareRU \#SafeSocial

[Insert graphic 1 from folder] 


\section{Appendix C.}

Recruitment poster and social media graphics.

\section{YOUNG WOMEN NEEDED FOR \\ INSTAGRAM STUDY}

\section{WHAT:}

We are looking into the acts of comparison and feelings of envy as a result of Instagram use with a goal of understanding more about social media's effect on mental health. Study Title: \#NeverEnough: Comparison \& Envy on Instagram

HOW:

In this study, you will be required to give two audiorecorded 30-minute, confidential interviews on separate days about your Instagram use and resulting feelings. These will take place at Ryerson.

WHY:

For your time, you will be given $\$ 20$ while contributing to a greater understanding of how social media use truly affects us.

WHO:

- You identify as a woman

- You are between the ages of 18-24 as of October 1, 2018

- You speak and understand fluent English

- You are a full-time undergraduate student at Ryerson University in the 2018-2019 academic year

- You have an active personal Instagram account

- Your Instagram account is set to public

- You check your personal Instagram feed at least once per day

- You post on your personal Instagram account at least once every 2 weeks

NEXT STEPS:

If you meet the above criteria and are interested in participating, please fill out the form at:

http://bit.ly/RUInstagramStudy

Ryerson University
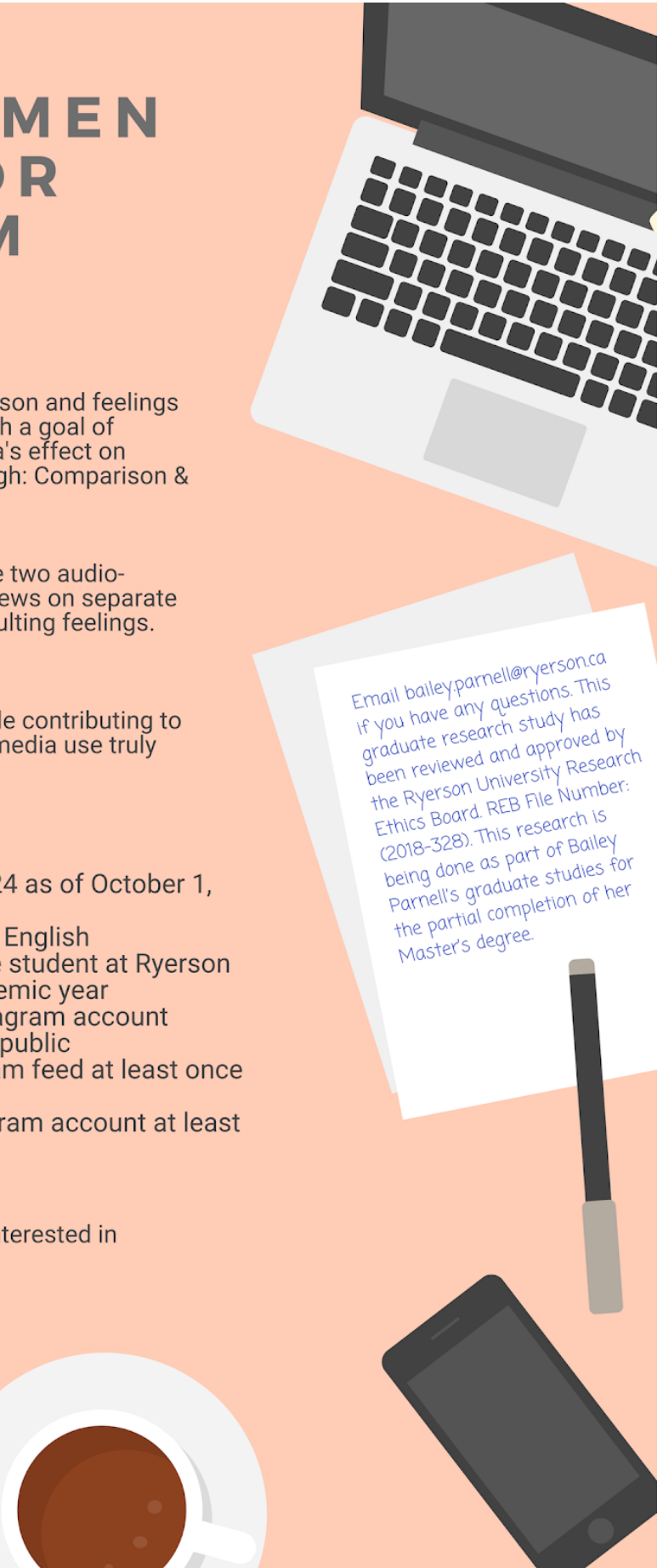

mail bailey.parnell@ryersonca balley auestions. This you have any questions this has graduate research study has by been reviewed and approvearch the Ryerson University Rumber: Ethics Board. REB fesearch is 1201328). This research is 2018 -328) This part of Balley being done as parte studies for parnell's graduatestion of her the partial comp Master's degree
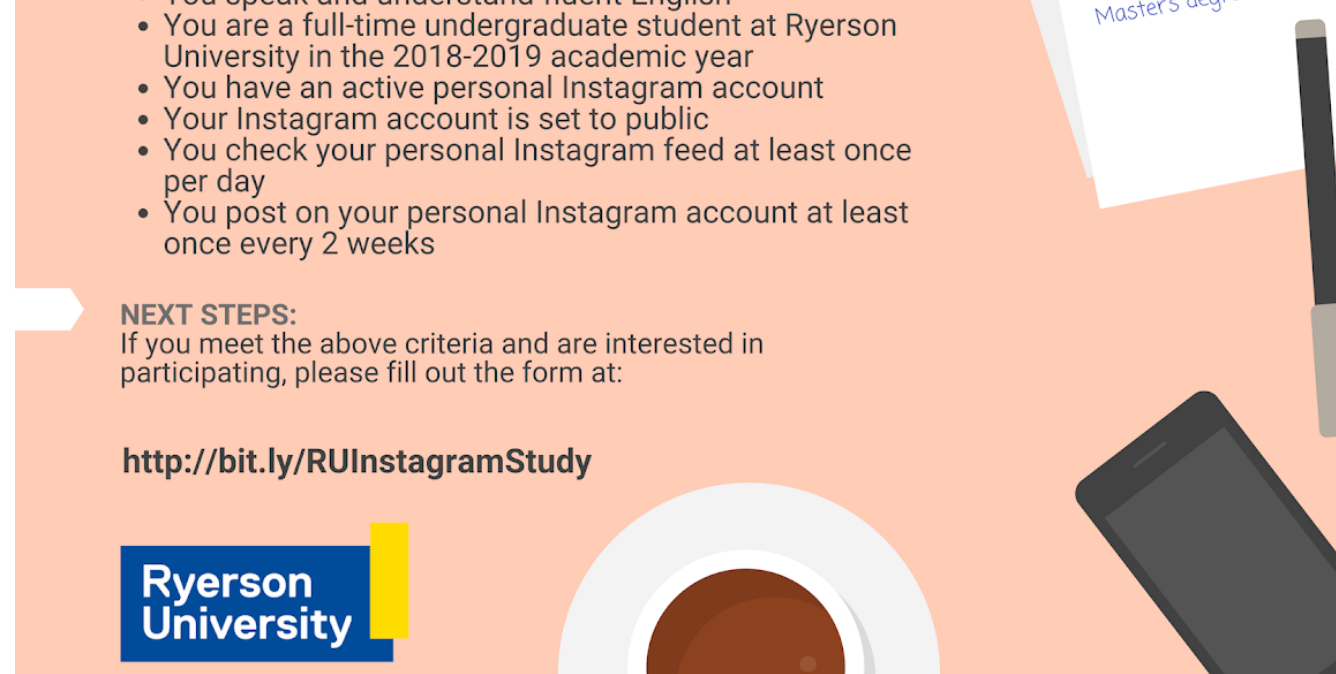

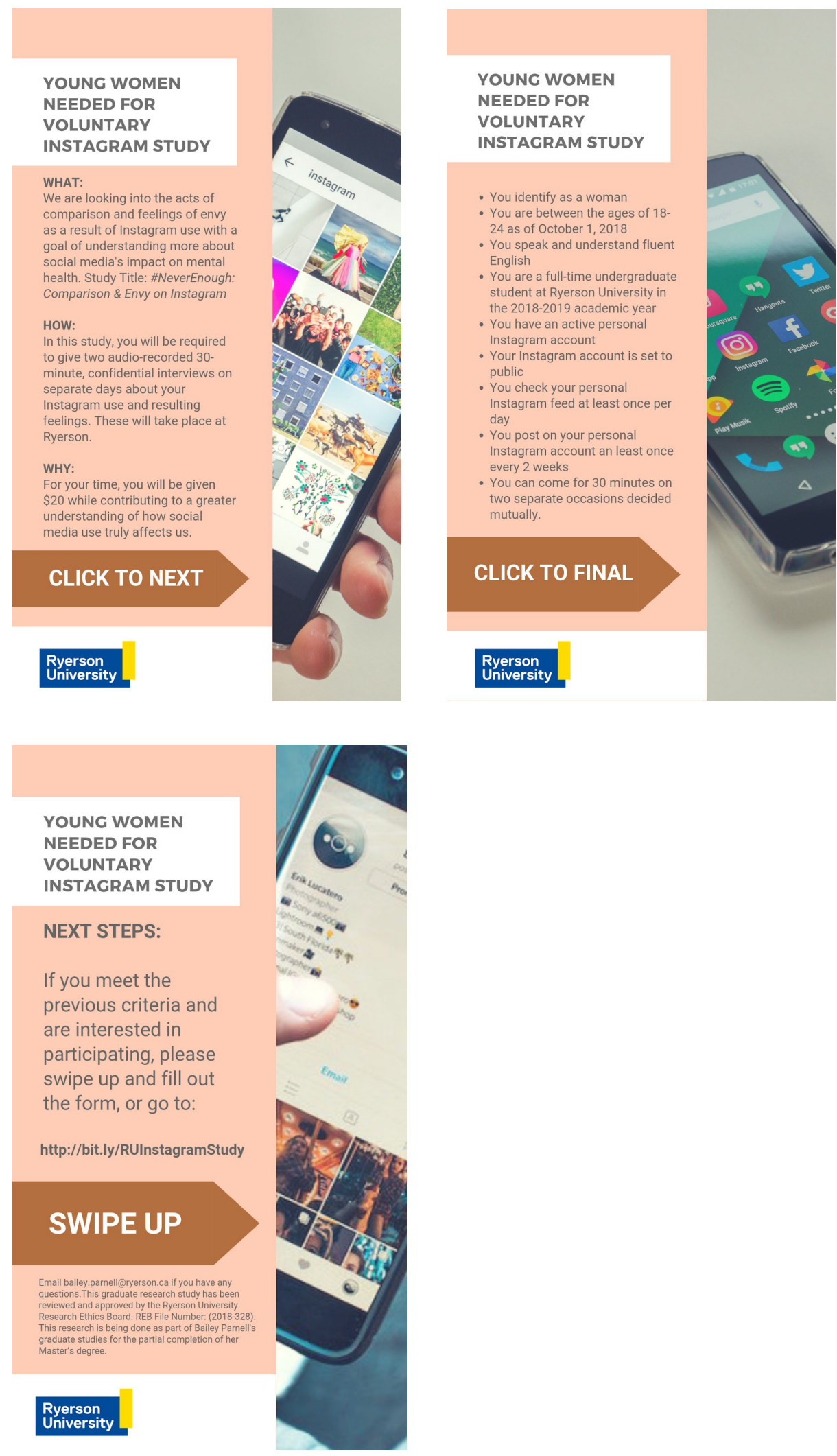


\section{Appendix D.}

\section{Initial Recruitment Form}

\section{YOUNG WOMEN NEEDED FOR VOLUNTARY INSTAGRAM STUDY}

This should take no more than 5 minutes to read and complete.

NAME OF STUDY:

\#NeverEnough: Social Media Comparison and Envy on Instagram

WHAT:

We are looking into the acts of comparison and feelings of envy as a result of Instagram use with a goal of understanding more about social media's effect on mental health.

HOW:

In this study, you will be required to give two 30 -minute, confidential interviews on separate days about your Instagram use and resulting feelings. Audio from these interviews will be recorded for use by the researcher. These will take place at Ryerson University.

WHY:

For your time, you will earn $\$ 20$ while contributing to a greater understanding of how social media use truly affects us.

WHO

You may participate in this study if you meet the following eligibility criteria:

- You identify as a woman

- You are between the ages of 18-24 as of October 1, 2018

- You speak and understand fluent English

- You are a full-time undergraduate student at Ryerson University in the 2018-2019 academic year

- You have an active personal Instagram account

- Your Instagram account is set to public

- You check your personal Instagram feed at least once per day

- You post on your personal Instagram account an least once every 2 weeks

NEXT STEPS:

If you meet the above criteria and are interested in participating, please proceed with this form.

RESEARCHER:

Bailey Parnell, Student, MA Communication \& Culture, PT

SUPERVISOR:

Dr. Anatoliy Gruzd, Canada Research Chair in Social Media Data Stewardship, and Associate Professor at the Ted Rogers School of Management

DISCLAIMER:

You will only be contacted if you are selected as a participant. This graduate research study has been reviewed and approved by the Ryerson University Research Ethics Board. REB File Number: (2018328). This is a voluntary study. Should you want to cancel this form at any time, simply close the browser window and no information will be kept. Should you finish this form and want to withdraw participation, or have any other questions, please email bailey.parnell@ryerson.ca.This research is being done as part of Bailey Parnell's graduate studies for the partial completion of her Master's degree.

${ }^{*}$ Required

\section{Email *}

We are collecting your email so that, if selected, we can contact you. If you are not selected, you will not receive any emails from us and your emai will be permanently deleted off our servers after June 2019. 
2. I understand that I may withdraw consent from this process at any time by closing my browser window. *

Mark only one oval.

Yes

3. I meet all of the eligibility criteria stated above. *

Mark only one oval.

Yes

4. I confirm that the information provided in this form is truthful and accurate. *

Mark only one oval.

Yes, the information is truthful and accurate.

No, the information is false.

5. If I am selected as a study participant, I consent to letting the researcher, Bailey Parnell, email me to set up interview times. *

Mark only one oval.

Yes, I consent.

No, I do not consent.

Powered by

i: Google Forms 


\section{Appendix E.}

Guiding interview questions for semi-structured interviews.

Interview 1

\section{Tell me a bit about yourself.}

Ideal answers to this question would include their program, areas of interest, jobs, area they live, etc. This will give me a general understanding of who they are in the way they choose to represent themselves.

\section{If you want to learn more about something do you want to know what others think of it?}

This is a softer question that would indicate the participant takes others opinions into account more. It may indicate the act of comparison without asking explicitly. Ideal answers would suggest they do like to run things by others.

\section{How much attention do you pay to how others do things compared to} you?

Some examples may include: how you dress, where you work, how you speak, or where you live.

This is another question that would indicate how the participant relates to the act of comparison in daily life. Ideal answers would suggest they do pay attention to how others do things.

\section{Do you find you compare yourself to others?}

This is a direct question that has the participant consider how they compare themselves to others offline. Ideal answers would suggest they do compare themselves to others so that we may see how it relates to Instagram comparison. 
5. Comparing yourself can go in many directions. [See diagram below (which I will show the participant)]. You could compare upwardly as in you see something else as better than you for some reason. You could compare neutrally, as in you compare and judge that you are even. Or, you could compare downwardly as in you see yourself as better for some reason. Do you think you engage in one direction of comparison more than another?
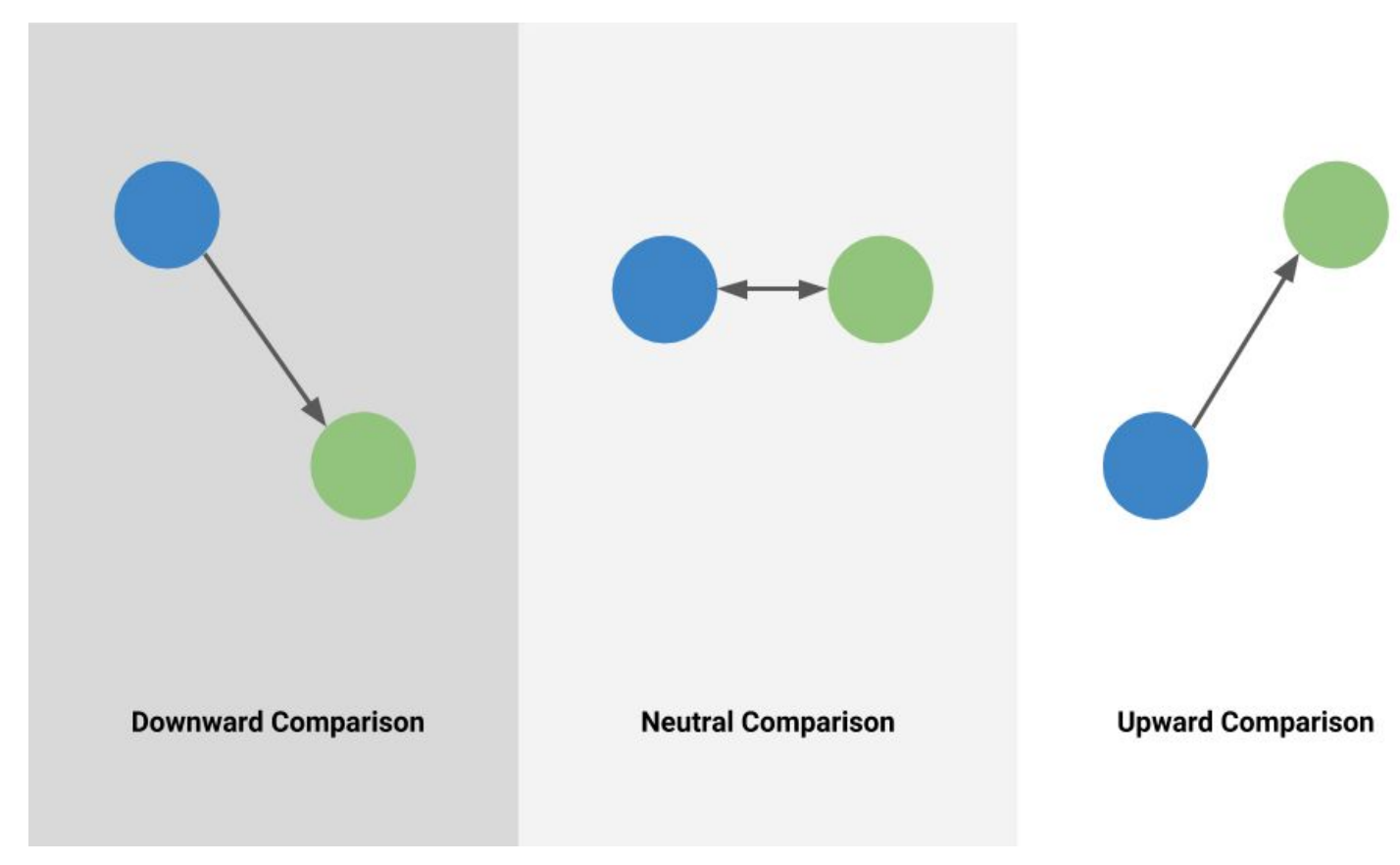

Types of comparison have been linked in previous research to differences in how the individual feels. I am interested in whether seeing yourself as higher or lower, figuratively speaking, affects how they compare or feel envy.

6. Is there an area of life you find yourself comparing more often? Some examples may include school grades or involvement, social media following, career, friends, significant others, personal skills, appearance, family, lifestyle, etc.

Why?

Given their phase of life, I am interested in what they compare most often, and to see if this lines up with Robert J. Havighurst's Developmental Task Theory. 
Interview 2

Now we are going to switch gears a bit, and narrow in on Instagram use.

7. How are you doing?

This is to establish rapport and get a sense of their current mindstate.

8. Have you thought about our last interview together? Are there any other thoughts you want to share?

This is to give them a chance to change or add to what they previously said.

9. Tell me about your Instagram use.

Follow-Ups:

Why did you join?

What do you like most/ least about Instagram

Do you take it seriously?

This question is to have them describe in their own words this relationship with Instagram. This will help me frame future questions.

10. What do you like to see most on Instagram?

Ideal answers to this question would include genres of photos such as "I like to see my friends and family," "I like looking at beauty influencers," or "I like travel photographers."

Follow-up:

Would you say this is most of your feed?

If not, what do you actually see most?

11. How do you feel when using Instagram?

Follow-Up:

How do you feel after using Instagram? 
In their own words, I want them to describe how using Instagram makes them feel. Ideal options would be clearly positive or negative feelings.

12. [OBSERVATION] Could you please pull out your Instagram feed and talk me through the first 5 photos? Only choose photos you feel comfortable showing me. If you need to keep scrolling, that's fine. Tell me what you think of them, how you might compare yourself, or anything else it makes you feel. [This will happen in the first and second interview.]

Since Instagram now runs in an algorithm, and not chronologically, the photos at the top of anyone's feed are curated based on what they look at and engage with most often - not who posted most recently. Doing this twice in the first and second interview will ensure variety and a stronger sample of the kind of content they look at. Ideally, they would explain their thoughts about what they see most.

13. Would you say you compare yourself on Instagram?

Follow-ups:

Would you say it is more, less, or about the same as offline? Why do you think that is?

I want to know if they experience comparison on Instagram specifically and if they feel it is hyper focused on the platform.

14. If separate from the first 5 photos we discussed, can you show me photos on Instagram that might make you compare yourself more?

If they have indicated they do compare themselves often, I want to see specifically what they compare to, and if there are trends among them in different participants.

15. Envy is defined by Webster's dictionary as the "painful or resentful awareness of an advantage enjoyed by another joined with a desire to possess the same advantage." That's a technical way of saying that you may majorly or slightly resent someone for having something you want. Would you say you experience envy as a result of using Instagram? 
I want to ensure the participants understand the definition of envy I am working with before they answer whether or not they are experiencing it. Ideal answers would be a yes or no and followed up by probes about how they experience it and why they think do or do not.

Follow-Ups:

How does envy present itself? What thoughts go through your mind?

Why do you think you [or do not] feel envy?

16. Are there any other feelings you experience often as a result of using Instagram? Some examples may include happiness, sadness, confidence, self-loathing, excitement, humour, depression, anxiety, calm, etc.

Comparison and envy may not be the only feelings Instagram use evokes. I want to give participants a chance to highlight other emotions in their own words.

17. Is there anything else you want to say about comparison and envy on Instagram. Any opinions on the topic?

After our time together, across two interviews, I believe the participants would have reflected a bit about the subject. I want to give them the chance to air out any opinions they may have formed that may be outside the scope of my guiding questions.

\section{Would you have any advice for younger kids using Instagram?}

Finally, I want to see if the participants would recommend similar or different strategies to younger children regarding Instagram use. This could be extremely interesting to see if they would recommend not using it, limiting it, building self-confidence, etc. 


\section{Appendix F.}

Consent form.

\section{Ryerson \\ University}

Graduate

Studies

\section{Ryerson University Consent Agreement}

You are being invited to participate in a research study. Please read this consent form so that you understand what your participation will involve. Before you consent to participate, please feel free to ask any questions to be sure you understand. Please find details of the study below.

\section{Study Title:}

\#NeverEnough: Social Media Comparison and Envy on Instagram

\section{Investigator:}

This research study is being conducted by Bailey Parnell, a graduate student in the Communications and Culture program at Ryerson University with the help of her supervisor, Dr. Anatoliy Grudz.

If you have any questions or concerns about the research, please feel free to contact:

Bailey Parnell at bailey.parnell@ryerson.ca.

\section{Purpose of the Study:}

This research will explore if young women are comparing themselves on Instagram and if that leads to feelings of envy, which have been previously linked to depression. Two 30-minute interviews will be conducted with 10 young women on different days. All participants must have met the following inclusion criteria:

- You identify as a woman

- You are between the ages of 18-24 as of October 1, 2018

- You speak and understand fluent English

- You are a full-time undergraduate student at Ryerson University in the 2018-2019 academic year

- You have an active personal Instagram account

- Your Instagram account is set to public 
- You check your personal Instagram feed at least once per day

- You post on your personal Instagram account at least once every 2 weeks

This study will contribute to the partial completion of Bailey Parnell's degree and the development of a thesis, a partial requirement of the MA in Communications and Culture at Ryerson University.

\section{What You Will Be Asked to Do:}

If you volunteer to participate in this study, you will be asked to sign this consent form and take part in two 30-minute interviews about your feelings in relation to envy and comparison on Instagram. Both interviews will be audio-recorded and transcribed.

At the beginning of the first interview, we will walk through and sign the consent form. This interview will inquire about your general Instagram use, what types of accounts you follow, what kind of content you like, if and how you compare yourself, etc. The second interview, on a separate predetermined day, will focus more on how your Instagram use has been since our first meeting, and will have you show me photos in your feed and narrate your thoughts.

These interviews will be held on the Ryerson campus within private rooms on the lower ground floor of the Podium building. This area of the university is dedicated to the department of Student Life, and the Career Centre, so no one who sees you will know why you are in that building if you don't want them to.

Approximately 8-11 months after your interviews, you will be emailed the findings and a copy of the final thesis if you select yes when asked below.

\section{Potential Benefits:}

The benefits to taking part in this research are the chance to engage in mindful reflection about your social media use. These conversations tend to be therapeutic in the colloquial sense of the word. Additionally, it is my aim that, with the help of our research, future research in this field will result in strategies people can use to improve their online experiences and reduce any negative experiences.

\section{Potential Risks to You As A Participant:}

The main risk in this research is that the interview questions in this study are designed to understand how you feel after interactions on Instagram, and more specifically, if you are comparing yourself and/or feeling envy. It is possible you 
might feel uncomfortable talking about personal feelings, especially if they are feelings of sadness, anxiety, or depression as a result of Instagram use.

To mitigate this risk, we are sharing as much about the process with you ahead of time. As a skilled facilitator and former staff member who managed student staff at Ryerson University, I have consulted counsellors at Ryerson's Centre for Student Development and Counselling (CSDC) ahead of time. In the case that you are majorly negatively triggered by our discussion, I am extremely familiar with the protocol for the CSDC and their same-day care model. I will happily take you there myself should you need it. If we are meeting outside business hours, I will still walk you there and find out when they are open next. I will also remain available to you via email for up to one year after the research is complete in case you need help or want to share more.

There is no accentuated risk of identities being revealed in this study, there is always a risk that a person is hacked, or their hardware stolen. To mitigate this risk, I have taken data storage and safety precautions outlined below in "Confidentiality \& Data Storage:"

\section{Confidentiality \& Data Storage:}

To keep your identity confidential, the emails collected in the initial recruitment survey will be permanently deleted off of Ryerson's Google Drive server after the interview phase is complete. Signed consent forms (such as this one) will be collected and kept in a locked filing cabinet in my home office.

Interviews will be conducted with me in a private room on the Ryerson campus. They will be recorded using a Zoom microphone. The SD card on which these are recorded will also remain only with me and stored in the same locked filing cabinet as the consent forms. After each interview, the audio will be immediately transferred to the secure Ryerson Google Drive and deleted off the SD card. The audio will also be immediately transferred to a separate password-protected hard drive.

Interview audio will be later transcribed by Rev.com, a service I have previously used that offers non-disclosure agreements and secure storage and transmitting using 128-bit SSL encryption, the highest level of security available. Once they transmit the files to me, Rev will delete them off their servers and I will save them on a password-protected hard drive. Since Rev.com hosts its servers in the US, the data on their servers are subject to US laws, including the USA Freedom Act. As such, US authorities may access the research data before it is permanently deleted.

All participants will be assigned code names and referred to only as such in the writing. Interview transcripts and audio files will be kept for 15 years after the 
completion of this research. This data and findings may contribute to future research in this area or by me, the researcher. After 15 years, they will be deleted permanently off my hard drives.

\title{
Data Dissemination:
}

The data that comes from this research will never be attached to a name when shared. The data and findings from the research will be shared on my personal website (http://baileyparnell.com) as well as through my personal social media (@BaileyParnell). It will also be disseminated via conference presentations, public speaking at non-academic events, and potentially through journals and a book later in life-though the last two are unconfirmed.

\section{Please indicate if you would like a copy of the final research paper sent to you?}

\author{
Yes 0 No ?
}

If you've answered yes, after the final thesis is submitted and approved by my program, a copy of the thesis will be emailed to you. Should you decide later you want to read the research, all completed research produced by Ryersons students is uploaded to the Ryerson Digital Repository at: https://digital.library.ryerson.ca.

\section{Incentives:}

You will be given $\$ 20$ total for participating in this research study. $\$ 10$ will be given to you at the beginning of the first interview and the remaining $\$ 10$ will be given to you at the beginning of the second interview. All will be in cash form. If you withdraw part-way through the first or second interview, you will still receive the $\$ 10$ for that interview. For example, if you drop out halfway through the first interview, you will still receive the $\$ 10$. If you drop out during the second interview, you will have received the full $\$ 20$ by then.

\section{Costs to Participation:}

Considering you are a full-time undergraduate student on Ryerson's, there should be no cost to participation that you would not otherwise have to incur coming to campus (eg. transit cost).

By agreeing to participate in this research, you are not giving up or waiving any legal right in the event that you are harmed during the research.

\section{Voluntary Participation:}


Participation in this study is completely voluntary. You can choose whether to be in this study or not. If any question makes you uncomfortable, you can skip that question. You may stop participating at any time and you will still be given the incentives described above. If you choose to stop participating, you may also choose to not have your data included in the study. Your choice of whether or not to participate will not influence your future relations with Ryerson University or the investigator, Bailey Parnell, involved in the research.

If you, for any reason, cause the investigator to be unsafe, the investigator also reserves the right to terminate the interview and your participation in this study.

The deadline to withdraw consent will be two weeks after your final interview. This will give you some time to reflect on what you've said.

\title{
Questions About the Study:
}

This is being sent to you ahead of time so you have time to read and reflect, and will also be talked through before your first interview. If you have any questions about the research now, please ask. If you have questions later about the research, you may contact Bailey Parnell at bailey.parnell@ryerson.ca or the supervisor of this research, Anatoliy Gruzd at gruzd@ryerson.ca.

This study has been reviewed by the Ryerson University Research Ethics Board. If you have questions regarding your rights as a participant in this study please contact:

\author{
Research Ethics Board \\ c/o Office of the Vice President, Research and Innovation \\ Ryerson University \\ 350 Victoria Street \\ Toronto, ON M5B $2 \mathrm{~K} 3$ \\ 416-979-5042 \\ rebchair@ryerson.ca
}

\section{Signatures and Consent}

1. I hereby consent to participating in this aforementioned research study and understand that I may withdraw that consent at any time during the process.

Printed Name

Signature

Date 
2. I hereby consent to my interview audio being recorded for the aforementioned research study and understand that I may withdraw that consent at any time during the process.

Printed Name

Signature

Date 


\section{Appendix G.}

Thematic coding definitions.

\begin{tabular}{|c|c|c|}
\hline Theme & Definition & Examples \\
\hline $\begin{array}{l}\text { Compares a } \\
\text { lot in general. }\end{array}$ & $\begin{array}{l}\text { The participant expressed } \\
\text { that they do feel they } \\
\text { compare themselves to } \\
\text { others a lot offline. }\end{array}$ & $\begin{array}{l}\text { "A lot. Basically, my whole life." } \\
\text { "I compare myself to other people a } \\
\text { lot." } \\
\text { "I notice how I'm different from other } \\
\text { people a lot." }\end{array}$ \\
\hline $\begin{array}{l}\text { Compares a } \\
\text { lot on } \\
\text { Instagram. }\end{array}$ & $\begin{array}{l}\text { The participant expressed } \\
\text { that they do feel they } \\
\text { compare themselves to } \\
\text { others a lot on Instagram. }\end{array}$ & $\begin{array}{l}\text { "I feel like it's more comparison online } \\
\text { than in person." } \\
\text { "I wanna say it's definitely online, for } \\
\text { sure. Outside I really won't think } \\
\text { anything of it... But I think 'cause it's } \\
\text { like a flood of just people looking their } \\
\text { best." } \\
\text { "Online I think I do it more because it's } \\
\text { what you follow that you find admirable } \\
\text { and when it's online there's more } \\
\text { access as well." }\end{array}$ \\
\hline $\begin{array}{l}\text { Upward social } \\
\text { comparison. }\end{array}$ & $\begin{array}{l}\text { The participant expressed } \\
\text { that they feel their } \\
\text { comparisons are often } \\
\text { upward in direction. }\end{array}$ & $\begin{array}{l}\text { "Upward comparison is a huge thing. If } \\
\text { anything, it would probably be neutral } \\
\text { or upward, I guess." } \\
\text { "If I'm looking to compare, it's usually, } \\
\text { 'how is this person better than me' in } \\
\text { this way." } \\
\text { "Upward comparison [most], probably. } \\
\text { 'They're harder-working than me,' } \\
\text { 'they're smarter than me."” }\end{array}$ \\
\hline $\begin{array}{l}\text { Neutral social } \\
\text { comparison. }\end{array}$ & $\begin{array}{l}\text { The participant expressed } \\
\text { that they feel their } \\
\text { comparisons are often } \\
\text { equal or neutral in } \\
\text { direction. }\end{array}$ & $\begin{array}{l}\text { "Neutral more often than the others. } \\
\text { Yeah. I sort of like, mind my own thing } \\
\text { in regards to, like, how I'm going or } \\
\text { where everything's at. So I'm 'Hey, I'm } \\
\text { doing my thing. You're doing your }\end{array}$ \\
\hline
\end{tabular}




\begin{tabular}{|c|c|c|}
\hline & & thing. Whatever.'” \\
\hline $\begin{array}{l}\text { Downward } \\
\text { social } \\
\text { comparison. }\end{array}$ & $\begin{array}{l}\text { The participant expressed } \\
\text { that they feel their } \\
\text { comparisons are often } \\
\text { downward in direction. }\end{array}$ & $\begin{array}{l}\text { "Personally I would not wear this. } \\
\text { That's the first thing that popped into } \\
\text { my head, but yeah, I don't know. I'm } \\
\text { not a fan of the purse." } \\
\text { "If I'm studying with a friend, and I see } \\
\text { how unprepared they are...I'd be like, } \\
\text { 'Okay, I got a better chance than them.' } \\
\text { I'm probably a mean friend for thinking } \\
\text { that, but I'm like, 'I think I got this." }\end{array}$ \\
\hline $\begin{array}{l}\text { Frustration } \\
\text { with } \\
\text { mindlessness. }\end{array}$ & $\begin{array}{l}\text { Participants express a } \\
\text { negative sentiment } \\
\text { associated with either the } \\
\text { amount of time they're } \\
\text { spending } \\
\text { "absentmindedly" on } \\
\text { Instagram or how they are } \\
\text { "wasting" the time they do } \\
\text { spend on Instagram, } \\
\text { regardless of how much. }\end{array}$ & $\begin{array}{l}\text { "It's a horrible thing. I use it to } \\
\text { procrastinate all the time. I'll have, like, } \\
\text { homework to do or something and I'll } \\
\text { be like, 'Okay, let me just go on } \\
\text { Instagram really quick,' but then I'll just } \\
\text { end up spending so much time on it, } \\
\text { just scrolling through, checking } \\
\text { notifications, sending people stuff... I } \\
\text { just waste a lot of time...I guess it's } \\
\text { kind of 'I could have spent my day or } \\
\text { my time more wisely doing other things } \\
\text { online."” } \\
\text { "I procrastinate." } \\
\text { "I'm wasting time." } \\
\text { "It'Il say that } 45 \text { minutes a day I'll } \\
\text { spend, which is a significant amount. } \\
\text { That's a lot. It's an hour of just going } \\
\text { through my [feed] which makes me feel } \\
\text { like shit. That's disgusting." }\end{array}$ \\
\hline $\begin{array}{l}\text { Cognitive } \\
\text { dissonance. }\end{array}$ & $\begin{array}{l}\text { Participants expressed } \\
\text { competing values and } \\
\text { behaviours such as } \\
\text { knowing something was } \\
\text { wrong, but doing it } \\
\text { anyways, loving and hating } \\
\text { someone they follow at the } \\
\text { same time, or } \\
\text { recommending to children }\end{array}$ & $\begin{array}{l}\text { "It's a battle between being like, 'I feel } \\
\text { like shit because of this other person. } \\
\text { That other person did nothing to me so } \\
\text { why do I feel like shit because this } \\
\text { other person.' Then I'm like, 'I feel like } \\
\text { shit because of myself.' Then you're } \\
\text { like, 'Great. So, I hate myself but at the } \\
\text { same time I don't." }\end{array}$ \\
\hline
\end{tabular}




\begin{tabular}{|c|c|c|}
\hline & $\begin{array}{l}\text { the exact opposite of how } \\
\text { they conduct themselves } \\
\text { online. } \\
\text { They do compare } \\
\text { themselves or feel } \\
\text { negative feelings, but then } \\
\text { rationalize or explain them } \\
\text { away. They still have a gut } \\
\text { reaction to the content, } \\
\text { but their minds try to make } \\
\text { them feel better. }\end{array}$ & $\begin{array}{l}\text { "I'Il see other people making things } \\
\text { artistically that I do. And I'm like, 'Well, } \\
\text { that's really good.' Or, 'They're doing it } \\
\text { and I'm not doing it,' and then that'Il } \\
\text { make me feel like shit, too. It's always, } \\
\text { as nice as the community is or any } \\
\text { community is there's still things that } \\
\text { hurt, I guess. It's more like a thing that I } \\
\text { do to myself 'cause I know they're not } \\
\text { doing it intentionally." } \\
\text { "She has a nice body. So I would say, } \\
\text { 'body goals.' She's fake, obviously, } \\
\text { had everything done but it's body } \\
\text { goals." }\end{array}$ \\
\hline $\begin{array}{l}\text { Social } \\
\text { pressure. }\end{array}$ & $\begin{array}{l}\text { Participants expressed } \\
\text { that it was the opinions of } \\
\text { others that makes them } \\
\text { act the way they do online, } \\
\text { even when it is to their } \\
\text { detriment. If they noted } \\
\text { pressure from friends, } \\
\text { society, or 'that's just how } \\
\text { things are done,' it was } \\
\text { recorded as a sentiment of } \\
\text { feeling social pressure. }\end{array}$ & $\begin{array}{l}\text { "I feel that pressure to stay connected } \\
\text { with people in that way, but it's not } \\
\text { really a genuine connection... I feel like } \\
\text { it's just a social game, that if you're not } \\
\text { in it, then you're kind of out of the } \\
\text { loop." } \\
\text { "Because they followed me initially... I } \\
\text { feel pressure to follow people back if } \\
\text { they're going to follow me, even though } \\
\text { I don't know them." } \\
\text { "We just follow each other. It's kind of } \\
\text { a mutual thing. People, you know of } \\
\text { each other, but you don't talk to each } \\
\text { other, I guess. You just follow each } \\
\text { other." }\end{array}$ \\
\hline
\end{tabular}

\section{Appendix H.}

Additional participant quotes supporting their frequent offline comparison.

I. In response to do you compare yourself to others, Jenny says: "Yes I do. Like studies, life, or yeah. A little bit of all factors of my life, I do." 
II. Blair's extended quote: "I compare myself to other people a lot, and I notice how I'm different from other people...I don't even know how to describe it, I feel like out of place a lot, I guess. Even back in [my small town] I did, because I was this, I don't know... I feel like I'm a very artsy person and a lot of people there really, really, it's all sports and, I don't know. Yeah. Here, I don't completely, like I love it here, and I love all the culture here but I feel like I'm still this person from a smaller town. I'm comparing how I act in contrast to how people act here who have lived here act."

\section{Appendix I.}

\section{Additional participant quotes supporting a difference between upward,} neutral, and downward social comparison.

I. Blair compares herself more upwardly to others: "I find now I'm either looking [at] how I am in contrast with other people or I'm looking up to people. Wishing I could be more like that."

II. Lola suggested that her upward comparisons could be made more impactful pending how influential the subject of comparison is: "If you see what other people do, if it's someone who's who you think is like, 'Oh, they're popular,' or who you think someone may be influential, and they do something. It's like, 'Oh, should I do that? Is that the right thing to do?'”

\section{Appendix J.}

Additional participant quotes showing the experiences of downward social comparison. 
I. Lola describes the experience of and guilt related to downward social comparison: "“'If I'm studying with a friend, and I see how unprepared they are. Sometimes I'm the one who's unprepared, but I see they're pretty unprepared, and I'm like, I wouldn't say something to them, but in my head, I'd be like, 'Okay, I got a better chance than them.' I'm probably a mean friend for thinking that, but I'm like, 'I think I got this.' I'm like, 'At least I'm not that unprepared.' I'm like, 'I probably started studying last night, too, but I'm not like that.'...Yeah, I think it does [make me feel better]. I think I'm like, 'That's fine, I'm gonna pass. I'm better."'

II. Ivy also explains her experiences with downward social comparison, but adds many qualifiers as to how she could feel that way: "If someone's below me, not below me, yikes. If someone's very bland, I will be like, 'I'm really happy that I'm able to embrace who I am without feeling nervous'... I don't wanna get cocky, and I'm not cocky, I really wouldn't say that I'm cocky. Even if I do that in my head I would never let it affect my outer appearance and I would still embrace them. I'm like, 'I'm doing work and you're not.' It's bad but it is true."

\section{Appendix K.}

\section{Additional participant quotes showing the areas they compare themselves}

\section{most.}

I. Jenny says she compares "a little bit [to] all types of groups in my life. It could be family, it could be friends, it could be complete strangers." 
II. Georgina echoed the sentiment that though she does not compare to everyone, she does, "definitely in the way that I dress. If there's certain people that dress the way I do. Or other people who are modeling on Instagram, I definitely pay attention to what they're doing. My hair and stuff like that. How I do my makeup. I definitely pay attention to what's going on in the makeup world. Fashion in general I guess."

\section{Appendix L.}

\section{Additional participant quotes showing the frequency of social comparison}

\section{on Instagram.}

I. When asked about offline versus online comparison Georgina explains, "I feel like it's more comparison online than in person." and furthermore that for her, the direction is "definitely upward. Especially online I guess because [everyone] wants to put their best face forward. Anyone can make themselves look good on social media. In person you're seeing who they really are and they're normal people. But on Instagram they look so good or doing all these fun things, but you don't see the rest of their lives that they don't put on social media."

II. Lola echoed this sentiment that seeing people's best selves changes the experience. Lola explains, "I think it's more [online] because offline you just see who you see... But I feel like on Instagram because everybody posts their best self, sometimes you do think about it and I feel like I do compare more on Instagram, based on their lifestyle or body or style." 
III. Lily also agreed: "Online I think I do it more because it's what you follow that you find admirable and when it's online there's more access as well."

\section{Appendix M.}

Additional participant quotes showing the experience of appearance-related social comparison on Instagram.

I. Lily added, "Online you get more of the looks and what people have materially... it's just the appearance. Appearance is material. Outside, offline is more professional and where they're going with their lives not what they have in their lives."

\section{Appendix N.}

Additional participant quotes showing the experience of envy after using

\section{Instagram.}

I. Ivy explains, "Literally as soon as you said 'envy,' I thought of ... That brings up a lot. I stalk my exes all the time. My recent ex, he just got a girlfriend, and I've just been freaking out. Her profile is private, so I can't even stalk her, but I'll stalk her through my ex. It's very much like I go crazy. I hate this chick, and I don't even know her. I've seen a couple pictures, and I'll see a tiny clip of her in a story, and I'Il be like, 'I hate her. I hate that she's with my ex. I hate all this. I hate seeing that they're having fun and that they're putting that out there.' It drives me crazy." 
II. Georgina expresses envy: "Yes. For sure. A lot of people like to put out all the luxuries they have, like their cars and all this stuff. It definitely makes me envy them, like, 'oh I want that. I want a Corvette.'”

\section{Appendix 0.}

\section{Additional participant quotes showing the collective frustration of the}

\section{mindlessness of Instagram.}

I. Eleanor explains, "Usually, [Instagram's time reminder] will say that 45 minutes a day I'll spend, which is a significant amount. That's a lot. It's an hour of just going through my [feed] which makes me feel like shit. That's disgusting... I think it's more like muscle memory in a sense. If I go on my phone, my first thing is just to click it even if I don't really want to or I don't think that I need to. It's just a habit."

II. Serena explains her inner dialogue, "Wait a second, I came on here to try to post something and I haven't. I've just spent the past hour looking at what other people are doing,' which doesn't do anything. That doesn't do anything for me. So that's kind of the hard part about it."

\section{Appendix P.}

Additional participant quotes showing the positive feelings after using

\section{Instagram.}

I. "Instagram is very much a spiritual place" for her since she can find and learn from people who dedicate their lives to the same kind of spirituality as her. for me." I do a lot of meditation and chakras and crystals. That's where I learn a lot 
more about it. 'Cause I find these people who dedicate their whole lives to it...that's really cool to me that I'm able to look at that and learn from people who've obviously been doing it longer."

\section{Appendix Q.}

\section{Additional participant quotes showing that similarity as a moderator of} comparison on Instagram.

I. Lily says, "I look down on myself with celebrities, especially when they're my age or younger... people that are my age like when you look at them and they're all successful already and like "Why aren't I like that?"

II. Ivy shares, "I'm very in myself and I like to embrace more of who I am to the fullest extent and if someone happens to do the same as me then it's just like, I almost feel bad I'm like, 'Oh, I thought I was kind of original,' but, no one's original."

\section{Appendix R.}

\section{Additional participant quotes showing that offline mood moderated}

\section{comparison on Instagram.}

I. Lola explains how her opinions can change pending her offline mood:

"Sometimes when you're just having a bad day and you're like, 'Screw this, go away with your good body.' Sometimes it's like, yes, if I go on Instagram after a good workout I'm like, 'That's nice,' 'going there'...Sometimes I'm just feeling myself, and I'm like, 'Yo, I'm cute, whatever,' like, 'I'm cute.' Then sometimes it's like, 'Oh, no. She's hot. Then there's me.'” 
II. In regards to her feelings as a result of comparing on Instagram, Jenny shared "I think it kind of matches my mood at the time, so if I'm feeling down I'll end up feeling even more like negative towards myself because I'm wasting time on Instagram and not being productive and stuff like that... like self loathing in a sense if I waste my whole day or if I have a lot of bad things that happen throughout the day... [I also feel] happiness, like again if I'm having a good day, like if I'm going online and I'm seeing bright colours, people smiling, that would make me happier too."

\section{Appendix S.}

\section{Additional participant quotes showing a cognitive dissonance related to} experiences of comparison on Instagram.

I. Serena showed us the mental dialogue she struggles with, "It's a battle between being like, 'I feel like shit because of this other person. That other person did nothing to me so why do I feel like shit because this other person.' Then I'm like, 'I feel like shit because of myself.' Then you're like, 'Great. So, I hate myself but at the same time I don't.' Then you're like, 'Why?'”

II. Eleanor demonstrated the ability to hold a competing belief about how Instagram comparison affects her as well as a competing belief about the subjects of comparison. She says, "When I see in my Explore page again, which is also helpful but also hindering, and I'll see other people making things artistically that I do. And I'm like, 'Well, that's really good,' or 'They're doing it and I'm not doing it,' and then that'Il make me feel like shit, too. It's always, as 
nice as the community is... there's still things that hurt, I guess. It's more like a thing that I do to myself 'cause I know they're not doing it intentionally."

III. Jenny showed a similar reaction when she expressed a distaste and said, "I know that people add filters, I know people pose a certain way so they can make themselves look a certain way, I know things aren't as real online... But then again, of course, there's still that comparison online, all the time."

IV. Georgina states, "[Instagram is] positive because it gets me to motivate myself. At the same time, negative, because I'm comparing what I have to what other people have, and that's not very healthy. I don't want to... I get motivated and all this stuff, and I compare what I don't have. But then at the same time it's kind of like being ungrateful for what I do have, in a sense. Which I don't like."

V. Though Georgina is someone who also currently compares her appearance on Instagram, her advice to younger girls was the opposite: "I had a lot of body issues when I was younger, so I definitely used it to compare myself to that. And I know that a lot of younger girls do that too, so I guess the advice would be to not just accept what you have, but kind of, not everything is what you think it is. A lot of things on Instagram are retouched, and people go in and they smooth their face, and they do all this stuff. Because you're so impressionable when you're younger, it's very in your face. You're like, 'I don't look like that.' You're not supposed to look like." 


\section{Appendix T.}

Additional participant quotes showing feelings of social pressure related to

\section{Instagram.}

I. Eleanor says, "I feel like if I'm posting something it's always like, 'Don't forget.

I'm here still.' Or thinking what if a friend will think, what if I'm not... 'Oh, Alex didn't like my photo,' or something."

II. Jenny says, "the times that I look good type of thing, I'll post on those times. It's just like a, 'Hi, I'm still alive' type of thing, like an update for whoever is following me, you know?" 


\section{Bibliography}

"\#StatusOfMind Social media and young people's mental health and wellbeing." Youth Health Movement, Royal Society of Public Health, 2017.

Academic Program Administration Contacts. (n.d.). Retrieved from Contact and Directory, Ryerson University website: https://www.ryerson.ca/contact/student/academic_contacts/

Acar, A. (2008). Antecedents and Consequences of Online Social Networking Behavior: The Case of Facebook. Journal of Website Promotion, 3(1-2), 62-83.

Alhabash, S., \& Ma, M. (2017). A Tale of Four Platforms: Motivations and Uses of Facebook, Twitter, Instagram, and Snapchat Among College Students? Social Media and Society, 3(1).

Andalibi, N., Ozturk, P., \& Forte, A. (2017). Sensitive Self-disclosures, Responses, and Social Support on Instagram: The Case of \#Depression. CSCW '17 Proceedings of the 2017 ACM Conference on Computer Supported Cooperative Work and Social Computing, $1485-1500$.

Arnett, J. J. (2000). Emerging Adulthood: A Theory of Development From the Late Teens Through the Twenties. American Psychologist, 55(5), 469-480. https://doi.org/DOI: 10.1037//0003-066X.55.5.469

Appel, H., Crusius, J., \& Gerlach, A. (2015). Social Comparison, Envy, And Depression On Facebook: A Study Looking At The Effects Of High Comparison Standards On Depressed Individuals. Journal of Social and Clinical Psychology, 34(4), 277-289. http://dx.doi.org/10.1521/jscp.2015.34.4.277 
Aspinwall, L. G., \& Taylor, S. E. (1993). Effects of social comparison direction, threat, and self-esteem on affect, self-evaluation, and expected success. Journal of Personality and Social Psychology, 64(5), 708-722. http://dx.doi.org/10.1037/0022-3514.64.5.708

Bargh, J., \& McKenna, K. (2004). The Internet and social life. Annual Review of Psychology, 55(1), 573-590.

Barthes, R. (1977). Rhetoric of the Image. In S. Heath (Trans.), Image-Music-Text (pp. 152-163). New York: Hill and Wang.

Bell, E. J., Owen, T., Brown, P. D., Hauka, C., \& Rashidian, N. (2017). The Platform Press: How Silicon Valley Reengineered Journalism. Tow Center for Digital Journalism, Columbia University.

Bernard, R. H. (2011). Research Methods in Anthropology: Qualitative and Quantitative Approaches. AltaMira Press.

Boak, A., Hamilton, H. A., Aldaf, E. M., Henderson, J. L., \& Mann, R. E. (2016). The Mental Health and Well-Being of Ontario Students, 1991-2015. Centre for Addiction and Mental Health, 43.

Boer, D. (2016). The Construction of an Online Identity A Case Study of Fashion Blog 'The Blonde Salad' and Founder Chiara Ferragni's Activities on Instagram (Masters Thesis). Leiden University, Leiden, Netherlands.

Bond, B. J. (2009). He Posted, She Posted: Gender Differences in Self-Disclosure on Social Network Sites. Rocky Mountain Communication Review, 6(2), 29-37. 
Bossetta, M. (2018). The Digital Architectures of Social Media: Comparing Political Campaigning on Facebook, Twitter, Instagram, and Snapchat in the 2016 U.S. Election. Journalism \& Mass Communication Quarterly, 95(2), 471-496. https://doi.org/10.1177/1077699018763307

Buunk, B. P., Collins, R., Taylor, S. E., Van Yperen, N. W., \& Dakof, G. A. (1990). The affective consequences of social comparison: Either direction has its ups and downs. Journal of Personality and Social Psychology, 59(6), 1238-1249. https://doi.org/DOI: 10.1037/0022-3514.59.6.1238

Cacioppo, J. T., \& Hughes, M. E. (2006). Loneliness as a Specific Risk Factor for Depressive Symptoms: Cross-Sectional and Longitudinal Analyses. Psychology and Aging, 21(1), 140-151.

Callan, M. J., Kim, H., \& Matthews, W. J. (2015). Age Differences in Social Comparison Tendency and Personal Relative Deprivation. Personality and Individual Differences, 87, 196-199. https://doi.org/10.1016/j.paid.2015.08.003

Casale, S., Gemelli, G., Calosi, C., Giangrasso, B., \& Fioravanti, G. (2019). Multiple exposure to appearance-focused real accounts on Instagram: Effects on body image among both genders. Current Psychology, (Journal Article), 1-10. https://doi.org/10.1007/s12144-019-00229-6

Chae, J. (2014). “Am I a Better Mother Than You?”: Media and 21st-Century Motherhood in the Context of the Social Comparison Theory. Communication Research, 42(4), 503-525. https://doi.org/10.1177/0093650214534969 
Chae, J. (2018). Reexamining the relationship between social media and happiness: The effects of various social media platforms on reconceptualized happiness. Telematics and Informatics, 35(6), 1656-1664. https://doi.org/10.1016/j.tele.2018.04.011

Charoensukmongkol, P. (2018). The Impact of Social Media on Social Comparison and Envy in Teenagers: The Moderating Role of the Parent Comparing Children and In-group Competition among Friends. Journal of Child and Family Studies, 27(1), 69-79. https://doi.org/10.1007/s10826-017-0872-8

Chen, J. (2020, January 15). Social media demographics to inform your brand's strategy in 2020. SproutSocial. https://sproutsocial.com/insights/new-social-media-demographics/\#IG-demos

Chua, T. H. H., \& Chang, L. (2015). Follow me and like my beautiful selfies: Singapore teenage girls' engagement in self-presentation and peer comparison on social media. Computers in Human Behavior, 55, 190-197. http://dx.doi.org/10.1016/j.chb.2015.09.011

Clarke, T. (2019, March 5). 22+ Instagram Stats That Marketers Can’t Ignore This Year. Retrieved July 2, 2019, from Hootsuite website: https://blog.hootsuite.com/instagram-statistics/

Clement, J. (2019). Distribution of Instagram users worldwide as of July 2019, by age and gender. Retrieved from Statistica website: https://www.statista.com/statistics/248769/age-distribution-of-worldwide-instag ram-users/ 
Collins, R. (1996). For better or worse: The impact of upward social comparison on self-evaluations. Psychological Bulletin, 119(1), 51-69. http://dx.doi.org.ezproxy.lib.ryerson.ca/10.1037/0033-2909.119.1.51

Crocker, J., \& Knight, K. M. (2015). Contingencies of Self-Worth. Current Directions in Psychological Science, 14(4). https://doi.org/10.1111/j.0963-7214.2005.00364.x.

Crocker, J., \& Wolfe, C. T. (2001). Contingencies of self-worth. Psychological Review, 108(3), 593-623. http://dx.doi.org/10.1037/0033-295X.108.3.593

"Cut social media use to reduce depression." (2018, November 10). The Daily Telegraph. Retrieved from http://ezproxy.lib.ryerson.ca/login?url=https://search-proquest-com.ezproxy.lib.r yerson.ca/docview/2131557667?accountid=13631

Dauenbeimer, D. G., Stablberg, D., Spreeman, S., \& Sedikides, C. (2002).

Self-Enhancement, Self-Verification, or Self Assessment The Intricate Role of Trait Modifiability in the Self-Evaluation Process. Revue Internationale De Psychologie Sociale, 15(3-4), 89-112.

David, E. (2019, July 18). Social media, screen time linked to depression in teens, study says. $A B C$ News. Retrieved from https://abcnews.go.com/Health/social-media-screen-time-linked-depression-te ens-study/story?id=64399137

Davila, J., Hershenberg, R., Feinstein, B. A., Gorman, K., Bhatia, V., \& Starr, L. R. (2012). Frequency and Quality of Social Networking Among Young Adults: Associations With Depressive Symptoms, Rumination, and Corumination. 
Psychology of Popular Media and Culture, 1(2), 72-86.

https://doi.org/doi:10.1037/a0027512

De Veirman, M., Cauberghe, V., \& Hudders, L. (2017). Marketing through Instagram influencers: The impact of number of followers and product divergence on brand attitude. International Journal of Advertising, 36(5), 798-828.

https://doi.org/10.1080/02650487.2017.1348035

De Vries, D. A., Möller, A. M., Wieringa, M. S., Eigenraam, A. W., \& Hamelink, K. (2018). Social Comparison as the Thief of Joy: Emotional Consequences of Viewing Strangers' Instagram Posts. Media Psychology, 21(2), 222-245. https://doi.org/10.1080/15213269.2016.1267647

Djafarova, E., \& Rushworth, C. (2017). Exploring the credibility of online celebrities' Instagram profiles in influencing the purchase decisions of young female users. Computers in Human Behavior, 68, 1-7. https://doi.org/10.1016/j.chb.2016.11.009

Donath, J. (2008). Signals in Social Supernets. Journal of Computer-Mediated Communication, 13(1), 231-251. https://doi.org/10.1111/j.1083-6101.2007.00394.

Duggan, M. (2015, August 19). The Demographics of Social Media Users. Retrieved from Pew Research Center website: https://www.pewinternet.org/2015/08/19/the-demographics-of-social-media-us ers/

Eco, U. (1978). A Theory of Semiotics (1st ed.). Indiana University Press. 
Ekman, M., \& Widholm, A. (2017). Political communication in an age of visual connectivity: Exploring Instagram practices among Swedish politicians. Northern Lights: Film \& Media Studies Yearbook, 15(1), 15-32. https://doi.org/10.1386/nl.15.1.15_1

Ellison, N. B., Steinfield, C., \& Lampe, C. (2007). The Benefits of Facebook “"Friends:”' Social Capital and College Students' Use of Online Social Network Site. Journal of Computer-Mediated Communication, 12, 1143-1168.

https://doi.org/doi:10.1111/j.1083-6101.2007.00367.x

Erikson, Eric. H. (1994). Identity: Youth and Crisis. W. W. Norton \& Company.

Festinger, L. (1954). A Theory of Social Comparison Processes. Human Relations, 7(2), 177-140. https://doi.org/10.1177/001872675400700202

Fisher, R. J. (1993). Social Indirect Desirability Questioning Bias and the Validity Of. Journal of Consumer Research, 20(2), 303-315.

Franzoi, S. L., Vasquez, K., Frost, K., Sparapani, E., \& Martin, J. (2012). Exploring Body Comparison Tendencies: Women Are Self-Critical Whereas Men Are Self-Hopeful. Psychology of Women Quarterly, 36(1).

Gibbons, F. X. (1986). Social comparison and depression: Company's effect on misery. Journal of Personality and Social Psychology, 51(1), 140-148. http://dx.doi.org/10.1037/0022-3514.51.1.140

Gibbons, F. X., \& Buunk, B. P. (1999). Individual differences in social comparison: Development of a scale of social comparison orientation. Journal of Personality 
and Social Psychology, 76(1), 129-142.

https://doi.org/DOI:10.1037/0022-3514.76.1.129

Goethals, G. R., \& Darley, J. (1977). Social comparison theory: An attributional approach. Social Comparison Processes: Theoretical and Empirical Perspectives, 86-109.

Grbich, C. (2013). Qualitative Data Analysis: An Introduction (2nd ed.). Los Angeles: SAGE Publications.

Greenwood, S., Duggan, M., \& Perin, A. (2016, November 11). Social Media Update 2016. Retrieved from Pew Research Center website: https://www.pewinternet.org/2016/11/11/social-media-update-2016/

Grogan, S. (1999). Body Image: Understanding Body Dissatisfaction in Men, Women and Children. Routledge.

Gruder, C. L. (1971). Determinants of social comparison choices. Journal of Experimental Social Psychology, 7(5), 473-489. https://doi.org/doi:10.1016/0022-1031(71)90010-2

Gruzd, A., Jacobson, J., Mai, P., \& Dubois, E. (2018). The State of Social Media in Canada 2017. Retrieved from https://socialmedialab.ca/2018/02/25/state-of-social-media-in-canada/

Guimond, S., Chatard, A., Martinot, D., Crisp, R. J., \& Redersdorff, S. (2006). Social Comparison, Self-Stereotyping, and Gender Differences in Self-Construals. Journal of Personality and Social Psychology, 90(2), 221-242. https://doi.org/DOI:10.1037/0022-3514.90.2.221 
Hall, S. (1980). Encoding / Decoding. Culture, Media, Language: Working Papers in Cultural Studies, 1972-79, 128-138.

Havighurst, R. J. (1967). Human Development and Education. David Mckay.

Hawi, N. S., \& Samaha, M. (2017). The Relations Among Social Media Addiction, Self-Esteem, and Life Satisfaction in University Students. Social Science Computer Review, 35(5), 576-586. https://doi.org/10.1177/0894439316660340 Helliwell, J. F., \& Putnam, R. D. (2004). The social context of well-being. Philosophical Transactions of the Royal Society, 359(1449), 1435-1446.

Ho, S. S., Lee, E. W. J., \& Liao, Y. (2016). Social Network Sites, Friends, and Celebrities: The Roles of Social Comparison and Celebrity Involvement in Adolescents' Body Image Dissatisfaction. Social Media + Society, 2(3), 2056305116664216. https://doi.org/10.1177/2056305116664216

Howard, J. (2019, July 15). Increasing social media use tied to rise in teens' depressive symptoms, study says. CNN Health. Retrieved from https://www.cnn.com/2019/07/15/health/social-media-depression-teens-study/i ndex.html

Ingvadóttir, A. B. (2014). The Relationship between Facebook Use and Loneliness: A Comparison Between High-School Students and University Students. Department of Psychology School of Business, Reykjavik University. Jay, M. (1993). The Noblest of the Senses: Vision from Plato to Descartes. In Downcast eyes: The denigration of vision in twentieth-century French thought (pp. 21-82). Berkeley, California: University of California Press. 
Jin, S. V., \& Muqaddam, A. (2018). "Narcissism 2.0! Would narcissists follow fellow narcissists on Instagram?" the mediating effects of narcissists personality similarity and envy, and the moderating effects of popularity. Computers in Human Behavior, 81, 31-41. https://doi.org/10.1016/j.chb.2017.11.042

Jin, S. V., Muqaddam, A., \& Ryu, E. (2019). Instafamous and social media influencer marketing. Marketing Intelligence \& Planning, 37(5), 567-579. https://doi.org/10.1108/MIP-09-2018-0375

Jonas, H. (1953). The Nobility of Sight. Philosophy and Phenomenological Research, $14,507-519$.

Jelenchick, L. A., Eickhoff, J. C., \& Moreno, M. A. (2016). "Facebook Depression?" Social Networking Site use and Depression in Older Adolescents. The Journal of Adolescent Health, 52(1), 128-130.

https://doi.org/10.1016/j.jadohealth.2012.05.008

Juarascio, A. S., Forman, E. M., Timko, C. A., Herbert, J. D., Butryn, M., \& Lowe, M. (2001). Implicit internalization of the thin ideal as a predictor of increases in weight, body dissatisfaction, and disordered eating. Eating Behaviors, 12, 207-213. https://doi.org/doi:10.1016/j.eatbeh.2011.04.004

Kang, Y. (2019). The relationship between contingent self-esteem and trait self-esteem. Social Behavior and Personality, 47(2). https://doi.org/10.2224/sbp.7575 Kathryn, G. L., Charanasomboon, S., Brown, C., Hiltunen, G., \& al, e. (2003). Internalization of the thin ideal, weight and body image concerns. Social 
Behavior and Personality, 31(1), 81.

doi:http://dx.doi.org.ezproxy.lib.ryerson.ca/10.2224/sbp.2003.31.1.81

Kim, J. W., \& Chock, T. M. (2015). Body image 2.0: Associations between social grooming on Facebook and body image concerns. Computers in Human Behavior, 48(Complete), 331-339. https://doi.org/10.1016/j.chb.2015.01.009

Kleemans, M., Daalmans, S., Carbaat, I., \& Anschütz, D. (2018). Picture Perfect: The Direct Effect of Manipulated Instagram Photos on Body Image in Adolescent Girls. Media Psychology, 21(1), 93-110.

https://doi.org/10.1080/15213269.2016.1257392

Korpinen, L., Pääkkönen, R., \& Gobba, F. (2018). Self-reported wrist and finger symptoms associated with other physical/mental symptoms and use of computers/mobile phones. International Journal of Occupational Safety and Ergonomics, 24(1), 82-90. https://doi.org/10.1080/10803548.2017.1282030

Krasnova, H., Wenninger, H., Widjaja, T., \& Buxmann, P. (2013, February). Envy on Facebook: A Hidden Threat to Users' Life Satisfaction? Hanna Krasnova1, *, Helena Wenninger2, Thomas Widjaja2, and Peter Buxmann. Presented at the 11th International Conference on Wirtschaftsinformatik, Leipzig, Germany. Krueger, D., \& Jin, L. (2008). Social Grooming In Primates: Mechanism. Retrieved September 29, 2019, from Social Grooming in Primates website: https://www.reed.edu/biology/professors/srenn/pages/teaching/web_2008/dklj_s ite_final/mechanism.html 
Kross, E., Verduyn, P., Demiralp, E., Park, J., Lee, S., Lin, N., \& Ybarra, O. (2013). Facebook use predicts declines in subjective well-being in young adults. Plos One, 1(8). https://doi.org/10.1371/journal.pone.0069841

Lalancette, M., \& Raynauld, V. (2019). The Power of Political Image: Justin Trudeau, Instagram, and Celebrity Politics. American Behavioral Scientist, 63(7), 888-924. https://doi.org/10.1177/0002764217744838

Lee, E., Lee, J.-A., Moon, J. H., \& Sung, Y. (2015). Pictures Speak Louder than Words: Motivations for Using Instagram. Cyberpsychology, Behavior, and Social Networking, 18(9). https://doi.org/10.1089/cyber.2015.0157

Leone, C. (2018, July 6). Which Social Media Sites Get The Most Engagement? Retrieved March 10, 2019, from WebStrategies website: www.webstrategiesinc.com/blog/which-social-media-sites-get-the-most-engage ment

Lewallen, J., \& Behm-Morawitz, E. (2016). Pinterest or Thinterest?: Social Comparison and Body Image on Social Media. Social Media + Society, 2(1), 2056305116640559. https://doi.org/10.1177/2056305116640559

Li, Y. (2019). Upward social comparison and depression in social network settings: The roles of envy and self-efficacy. Internet Research, 29(1), 46-59. https://doi.org/10.1108/ IntR-09-2017-0358

Lin, J.-H. T. (2019). Strategic Social Grooming: Emergent Social Grooming Styles on Facebook, Social Capital and Well-Being. Journal of Computer-Mediated Communication, 24(3), 90-107. https://doi.org/10.1093/jcmc/zmz002 
Liu, C., \& Ma, J. (2018). Social media addiction and burnout: The mediating roles of envy and social media use anxiety. Current Psychology. https://doi.org/10.1007/s12144-018-9998-0

Maares, P., \& Hanusch, F. (2018). Exploring the boundaries of journalism: Instagram micro-bloggers in the twilight zone of lifestyle journalism. Journalism, (Journal Article), 146488491880140. https://doi.org/10.1177/1464884918801400

Massey, N. (2019, July 16). Social media "causing teenage depression." Belfast Telegraph. Retrieved from http://ezproxy.lib.ryerson.ca/login?url=https://search-proquest-com.ezproxy.lib .ryerson.ca/docview/2258065747?accountid=13631

McGuirk, K. (2017). GET IT, GIRL! An Exploration Of "Fitspiration" Content On Instagram Using Visual Social Semiotics And Social Comparison Theory [Masters Research Paper]. Ryerson University.

McLeod, S. (2018). Cognitive Dissonance. Retrieved from SimplyPsychology website: https://www.simplypsychology.org/cognitive-dissonance.html

McLuhan, M., Fiore, Q., \& Agel, J. (1967). The Medium is the Massage: An Inventory of Effects. Bantam Books.

Mitchell, W. J. T. (1995). Picture Theory: Essays on Verbal and Visual Representation. University of Chicago Press.

Morse, S., \& Gergen, K. J. (1970). Social comparison, self-consistency, and the concept of self. Journal of Personality and Social Psychology, 16(1), 148-156. https://doi.org/DOI:10.1037/h0029862 
Nederhof, A. J. (1985). Methods of coping with social desirability bias: A review. European Journal of Social Psychology, 15(3), 263-280.

Nesi, J., \& Prinstein, M. J. (2015). Using Social Media for Social Comparison and FeedbackSeeking: Gender and Popularity Moderate Associations with Depressive Symptoms. Journal of Abnormal Child Psychology, 43(8), 1427-1438. https://doi.org/doi:10.1007/s10802-015-0020-0.

O'Connell, D. (2018). Selfie: Instagram and the United States Congress. Social Media + Society, 4(4), 205630511881337. https://doi.org/10.1177/2056305118813373

O’Keefe, G. S., \& Clarke-Pearson, K. (2011). Clinical Report-The Impact of Social Media on Children, Adolescents, and Families (Clinical Report No. 127.4). Retrieved from American Academy of Pediatrics website: https://pediatrics.aappublications.org/content/127/4/800

O’Reilly, M., \& Dogra, N. (2017). Interviewing Children and Young People for Research. SAGE Publications.

O’Reilly, M., \& Parker, N. (2014). Doing Mental Health Research with Children and Adolescents: A Guide to Qualitative Methods. SAGE Publications.

Our Story. (n.d.). Retrieved March 12, 2019, from Instagram.com website: https://instagram-press.com/our-story

Pantic, I., Damjanovic, A., Todorovic, J., Topalovic, D., Bojovic-Jovic, D., Ristic, S., \& Pantic, S. (2012). Association Between Online Social Networking and Depression in High School Students: Behavioural Physiology Viewpoint. Psychiatria Danubina, 24(1), 90-93. 
Primack, B. A., Shensa, A., Escobar-Viera, C., Barrett, E. L., Sidani, J. E., Colditz, J. B., \& James, A. E. (2017). Use of Multiple Social Media Platforms and Symptoms of Depression and Anxiety: A Nationally-Representative Study among U.S. Young Adults. Computers in Human Behavior, 69, 1-9.

Rizzolatti, G., \& Fabbri-Destro, M. (2009). Premotor Cortex in Primates: Dorsal and Ventral. Encyclopedia of Neuroscience. https://doi.org/10.1016/B978-008045046-9.01320-6

Rosenberg, M. (1965). Society And The Adolescent Self-Image. Princeton University Press.

Sedikides, C. (1993). Assessment, enhancement, and verification determinants of the self-evaluation process. Journal of Personality and Social Psychology, 65(2), 317.

Sedikides, C., \& Strube, M. J. (1997). Self-Evaluation: To Thine Own Self Be Good, To Thine Own Self Be Sure, To Thine Own Self Be True, and To Thine Own Self be Better. Advances in Experimental Social Psychology, 29, 209-269. https://doi.org/10.1016/S0065-2601(08)60018-0

Sheldon, P. (2008). The Relationship between Unwillingness-to-Communicate and Students' Facebook use. Journal of Media Psychology, 20(2), 67-75.

Sheldon, P., \& Bryant, K. (2016). Instagram: Motives for its use and relationship to narcissism and contextual age. Computers in Human Behavior, 58, 89-97. 
Slater, A., Varsani, N., \& Diedrichs, P. C. (2017). fitspo or \#loveyourself? The impact of fitspiration and self-compassion Instagram images on women's body image, self-compassion, and mood. Body Image, 22(Journal Article), 87-96. https://doi.org/10.1016/j.bodyim.2017.06.004

Smith, A., \& Anderson, M. (2018). Social Media Use 2018: Demographics and Statistics. Pew Research Center: Internet, Science \& Tech. Retrieved from www.pewinternet.org/2018/03/01/social-media-use-in-2018/

Social media linked to higher risk of depression in teen girls. (2019, January 3). Retrieved from https://www.reuters.com/article/us-health-depression-socialmedia/social-medi a-linked-to-higher-risk-of-depression-in-teen-girls-idUSKCN1OY00I

Social media use linked to depression in teens: Study. (2019, July 16). Aljazeera. Retrieved from https://www.aljazeera.com/news/2019/07/social-media-linked-depression-teen s-study-190716145551382.html

Soubelet, A., \& Salthouse, T. A. (2011). Influence of Social Desirability on Age Differences in Self-Reports of Mood and Personality vol. 79, no. 4, 2011. Pp. 741-762. Journal of Personality, 79(4), 741-762.

Steers, M.-L. N., Wickham, R. E., \& Acitelli, L. K. (2014). Seeing Everyone Else's Highlight Reels: How Facebook Usage is Linked to Depressive Symptoms. 
Journal of Social and Clinical Psychology, 33(8), 701-731.

http://dx.doi.org/101521jscp2014338701

Stewart, T. L., Chipperfield, J. G., Ruthig, J. C., \& Heckhausen, J. (2012). Downward social comparison and subjective well-being in late life: The moderating role of perceived control. Aging and Mental Health, 1-11.

http://dx.doi.org/10.1080/13607863.2012.743963

Stevens, A., \& Price, J. (2000). Attachment, Rank, and Psychiatry. In Evolutionary Psychiatry: A New Beginning (2nd ed., pp. 44-59). Routledge.

Stickland, A. C. (2014). Exploring the Effects of Social Media Use on the Mental Health of Young Adults. University of Central Florida Orlando, Florida.

Suls, J., Martin, R., \& Wheeler, L. (2002). Social comparison: Why, with whom, and with what effect? Current Directions in Psychological Science, 11(5), 159-163. https://doi.org/doi:10.1111/1467-8721.00191

Tandoc, E. C., Ferrucci, P., \& Duffy, M. (2015). Facebook use, Envy, and Depression among College Students: Is Facebooking Depressing? Computers in Human Behavior, 43, 139-146. https://doi.org/10.1016/j.chb.2014.10.053

Taylor, S. E., \& Lobel, M. (1989). Social comparison activity under threat: Downward evaluation and upward contacts. Psychological Review, 96(4), 569-575.

Tesser, A., \& Campbell, J. (1982). Self-evaluation maintenance and the perception of friends and strangers. Journal of Personality, 50(3), 261-279. https://doi.org/doi:10.1111/j.1467-6494.1982.tb00750.x 
The Pictorial Turn. (2015, May 9). Retrieved July 2, 2019, from Scribd.com website: https://www.scribd.com/document/264705357/The-Pictorial-Turn

Thorsteinsson, E. B., \& Davey, L. (2014). Adolescents' Compulsive Internet Use and Depression: A Longitudinal Study. Open Journal of Depression, 3(1), 13-17. https://doi.org/DOI: 10.4236/ojd.2014.31005

Tiggemann, M., Hayden, S., Brown, Z., \& Veldhuis, jolanda. (2018). The effect of Instagram "likes" on women's social comparison and body dissatisfaction. Body Image, 26, 90-97. https://doi.org/10.1016/j.bodyim.2018.07.002

Tiggemann, M., Polivy, J., \& Hargreaves, D. (2009). The Processing of Thin Ideals in Fashion Magazines: A Source of Social Comparison or Fantasy? Journal of Social and Clinical Psychology, 28(1), 73-93. https://doi.org/10.1521/jscp.2009.28.1.73

Wagner, C., Aguirre, E., \& Sumner, E. M. (2016). The relationship between Instagram selfies and body image in young adult women. First Monday, 21(9). https://doi.org/10.5210/fm.v21i9.6390

Wang, J.-L., Wang, H.-Z., Gaskin, J., \& Hawk, S. (2017). The Mediating Roles of Upward Social Comparison and Self-esteem and the Moderating Role of Social Comparison Orientation in the Association between Social Networking Site Usage and Subjective Well-Being. Frontiers in Psychology, 8. https://doi.org/doi: 10.3389/fpsyg.2017.00771 
Wayment, H. A., \& Taylor, S. E. (1995). Self-evaluation processes: Motives, information use, and self-esteem. Journal of Personality, 63(4), 729-757. https://doi-org.ezproxy.lib.ryerson.ca/10.1111/j.1467-6494.1995.tb00315.x

Weinstein, E. (2018). The social media see-saw: Positive and negative influences on adolescents' affective well-being. New Media \& Society, 20(10), 3597-3623. https://doi.org/10.1177/1461444818755634

White, J. B., Langer, E. J., Yariv, L., \& Welch IV, J. C. (2006). Frequent Social Comparisons and Destructive Emotions and Behaviors: The Dark Side of Social Comparisons. Journal of Adult Development, 13(1), 36-44. https://doi.org/DOI: $10.1007 / \mathrm{s} 10804-006-9005-0$

Williams, R. (1985). Culture and Society 1780-1950. Penguin.

Wills, T. (1981). Downward comparison principles in social psychology. Psychological Bulletin, 90(2), 245-271. http://dx.doi.org.ezproxy.lib.ryerson.ca/10.1037/0033-2909.90.2.245

Woods, H. C., \& Scott, H. (2016). Sleepyteens: Social Media use in Adolescence is Associated with Poor Sleep Quality, Anxiety, Depression and Low Self-Esteem. Journal of Adolescence, 51, 41-49.

Valkenburg, P. M., Jochen, P., \& Schouten, A. P. (2006). Friend Networking Sites and Their Relationship to Adolescents' Well-Being and Social Self-Esteem. Cyberpsychology and Behaviour, 9(5).

Veblen, T. (2007). The Theory of the Leisure Class. Oxford University Press. 
Ventura, R., Majolo, B., Koyama, N. F., Hardie, S., \& Schino, G. (2006). Reciprocation and interchange in wild Japanese macaques: Grooming, cofeeding, and agonistic support. American Journal of Primatology, 68(12), 1138-1149. https://doi.org/10.1002/ajp.20314

Vogel, E. A., Rose, J. P., Roberts, L. R., \& Eckles, K. (2014). Social Comparison, Social Media, and Self-Esteem. Psychology of Popular Media Culture, 3(4), 206-222. http://dx.doi.org/10.1037/ppm0000047 